\title{
Springer
}

Draft Manuscript for Review

\section{Spray-dried Ancellotta red wine: natural colorant with potential for food applications}

\begin{tabular}{|r|l|}
\hline Journal: & European Food Research and Technology \\
\hline Manuscript ID & EFRT-19-1026.R1 \\
\hline Manuscript Type: & Review article \\
\hline Dute Submitted by the & n/a \\
\hline Complete List of Authors: & $\begin{array}{l}\text { Alvarez Gaona, Izmari; Pontificia Universidad Católica Argentina, } \\
\text { Laboratorio de Alimentos ; Consejo Nacional de Investigaciones } \\
\text { Cientificas y Tecnicas } \\
\text { Fanzone, Martín ; Estación Experimental Agropecuaria Mendoza } \\
\text { Sari, Santiago ; Estación Experimental Agropecuaria Mendoza } \\
\text { Assof, Mariela ; Estación Experimental Agropecuaria Mendoza } \\
\text { Pérez, María Dolores ; Estación Experimental Agropecuaria Mendoza } \\
\text { Chirife, Jorge ; Pontificia Universidad Católica Argentina, Laboratorio de } \\
\text { Alimentos } \\
\text { Zamora , María Clara ; Pontificia Universidad Católica Argentina, } \\
\text { Laboratorio de Alimentos ; Consejo Nacional de Investigaciones } \\
\text { Cientificas y Tecnicas }\end{array}$ \\
\hline Keywords: & \begin{tabular}{l} 
Ancellotta, red wine, spray-drying, food colorant, anthocyanins \\
\hline
\end{tabular} \\
\hline
\end{tabular}

\section{SCHOLARONE" Manuscripts}




\section{"Spray-dried Ancellotta red wine: natural colorant with potential for food applications"}

Izmari Jasel Alvarez Gaona ${ }^{(1)(2)}$; Martín Fanzone ${ }^{(3)}$; Santiago Sari (3); Mariela Assof ${ }^{(3)}$; Dolores Pérez ${ }^{(3)}$; Jorge Chirife ${ }^{(1)}$; María Clara Zamora ${ }^{(1)(2)}$

(1) Facultad de Ingeniería y Ciencias Agrarias, Pontificia Universidad Católica Argentina, Av. Alicia Moreau de Justo 1516-1560, C1107AFF CABA.

(2) Consejo Nacional de Investigaciones Científicas y Técnicas (CONICET), Godoy Cruz 2290, CABA, Argentina.

(3) Estación Experimental Agropecuaria Mendoza, Instituto Nacional de Tecnología Agropecuaria (EEA Mendoza INTA). San Martin 3853, (5507) Luján de Cuyo, Mendoza, Argentina.

Corresponding author:

izmarialvarez@uca.edu.ar

+5491150607367

ID $0000-0001-6411-729 \mathrm{X}$

\section{Acknowledgments}

Authors acknowledge financial support from Facultad de Ingeniería y Ciencias Agrarias, Pontificia Universidad Católica Argentina. 


\begin{abstract}
Ancellotta red wine (Vitis vinifera L.) was encapsulated by spray-drying (inlet and outlet temperatures were $145^{\circ} \mathrm{C}$ and $70{ }^{\circ} \mathrm{C}$, respectively) to obtain a wine powder with a low water activity (aw) using maltodextrin DE10 as an encapsulating agent. The retention of Total Monomeric Anthocyanins (TMA) in the wine powder was found to be greater than $80 \%$. Anthocyanins profile of Ancellotta liquid wine and wine powder were characterized by using HPLC-DAD and thirty-three compounds were identified. The wine powder was stored under two different water activity values (aw 0.25 and aw 0.33 ). Furthermore, the TMA (pH differential method), total anthocyanins and malvidin-3-glucoside were determined by HPLC-DAD for up to 90 days' storage at $38{ }^{\circ} \mathrm{C}$. Total anthocyanins and malvidin-3glucoside decreased very slowly during storage. The stability of anthocyanins and color differences $\left(\Delta \mathrm{E}^{*}{ }_{\mathrm{ab}}\right)$ in $1 \%$ wine powder solution at different $\mathrm{pHs}$ and temperatures were evaluated. These results indicated that Ancellotta wine powder has the potential to be used as a food colorant in low $\mathrm{pH}$ and low water activity foods.
\end{abstract}

Keywords: Ancellotta; red wine; spray-drying; food colorant; anthocyanins. 
Anthocyanins are natural pigments found in flowers, vegetables, fruits and foods. Examples can be seen in tea and wine with an extensive range of colors including red, blue and purple hues $[4,5]$. Anthocyanins are also beneficial to health as they act as antioxidants that scavenge free radicals and decrease the oxidative effect of the blood by donating protons to highly reactive radicals [4]. Research found that regular intake of anthocyanins may decrease the potential of contracting cancer, cardiac diseases, Alzheimer's disease, and diabetes $[3,6,7]$.

Due to the enormous potential of natural anthocyanins as healthy pigments, there is an increasing number of reports in the literature regarding their purification and separation from plant tissues $[4,8]$

Utilization of anthocyanins as food colorants have two main drawbacks: a) In aqueous medium such as foods, anthocyanins undergo reversible structural transformations that are $\mathrm{pH}$ dependent, with concomitant changes in color [8-10]; b) The thermal instability of anthocyanins during food processing and storage acts as an impediment to their use. For this reason, the anthocyanins are encapsulated to retain their color and improve stability [11].

It is well known that red wines have a significant amount of anthocyanins responsible for color [12], and cv. Ancellotta stands out among them for its extremely high concentration of anthocyanins. The red-skinned variety of Ancellotta is typically grown in North-West Italy. Outside Italy this variety is cultivated in Brazil, in the southeast of Switzerland and in Argentina; because it produces wines of very good color suitable for blending. In Argentina the surface of Ancellotta registered in 2017, by Department of Statistics and Market Studies of INV (National Institute of Viticulture), a total of 1,313 ha cultivated, which represents $0.6 \%$ of the total vine of the country. The number of hectares of Ancellotta throughout the country has increased by $824 \%(+1,171$ ha) in the period $2008-2017$. The province of Mendoza has the largest number of Ancellotta in the country, reaching 1,103 ha $(84 \%)$ in $2017[13]$. 
Spray-drying is a technique used in the encapsulation of various bio-products. During the process, the "active" materials are trapped within a protective matrix of the encapsulating agent. This technique has been widely used for drying heat sensitive foods and pharmaceutical products [14], due to the rapid evaporation of water from the droplets formed $[15,16]$. Encapsulation plays a key role in maintaining the stability of bioactive compounds, therefore, improving their shelf life.

Recently, Alvarez et al., [17] showed that a powder of red wine from cv. Cabernet sauvignon might be obtained by spray-drying leading to a free-flowing product with a good storage stability of anthocyanins, as long as the water activity of the powder remained low.

The objectives of the present study were to obtain a spray-dried encapsulated Ancellotta wine from Mendoza (Argentina) and evaluate its potential use as a colorant in food. The anthocyanins profile of the wine powder was evaluated using HPLC-DAD and the stability of the powder during storage was also monitored. Additionally, the color behavior of powder solutions at different $\mathrm{pH}$, temperatures, and times was evaluated. As far as we know, there is no published article to date about spray-drying of Ancellotta wine and the potential use of wine powder as a natural colorant in food.

\section{MATERIALS AND METHODS}

\section{Reagents}

The encapsulating agent used for spray-drying was maltodextrin DE10 (Dextrose Equivalent 10-MD10) (Ingredion S.A, Argentina). The salts (analytical grade) used to control the relative humidity (RH \%) were magnesium chloride (33\%), potassium carbonate (43\%), sodium bromide (58\%), sodium chloride (75\%), and ammonium sulfate (80\%), purchased from Biopack (Argentina). The FolinCiocalteu reagent was obtained from Merck (Darmstadt, Germany). Standards of gallic acid [149-917] and malvidin-3-glucoside chloride [7228-78-6] were supplied by Sigma Aldrich (St. Louis, USA). Formic acid (98\%), chromatography grade methanol and acetonitrile were purchased from Merck (Darmstadt, Germany). All reactive chemicals were analytical grade or superior. Ultra-pure water was obtained from a RiO/Elix3-Sinergy185 purification system (Millipore, Sao Pablo, Brazil). Cellulose filters ( $3 \mu \mathrm{m}$ pore size) and ( $0.45 \mu \mathrm{m}$ pore size) nylon membrane were supplied by Microclar (Buenos Aires, Argentina).

\section{Red wine}

Ancellotta experimental wine (2015 harvest) from La Consulta (Mendoza, Argentina), produced by Experimental Agricultural Station Mendoza, National Institute of Agricultural Technology (INTA), was used as a raw material $(\mathrm{pH} 3.95$, dry extract $3.15 \%(\mathrm{w} / \mathrm{w})$, alcohol $14.8 \%(\mathrm{v} / \mathrm{v})$, total acidity $5.3 \mathrm{~g}$ tartaric $\operatorname{acid} / \mathrm{L})$. 
Spray-drying

A mixture of $13.5 \%(\mathrm{w} / \mathrm{w})$ maltodextrin DE10 and $86.5 \%(\mathrm{w} / \mathrm{w})$ red wine was prepared and resulting solution was spray-dried with a mini spray dryer Buchi model B-290 (Büchi Laboratoriums Technik, Switzerland), under the following operating conditions: feed flow rate $600 \mathrm{~g} / \mathrm{h}$; drying air inlet temperature $145{ }^{\circ} \mathrm{C}$, and outlet temperature (average) $70{ }^{\circ} \mathrm{C}$; flow meter spraying air (rotameter) 30 $\mathrm{mm}$; 0.23 bar pressure drop; and $439 \mathrm{~L} / \mathrm{h}$ actual volume flow (at standard temperature and pressure). The yield of spray-drying was $59 \pm 3 \%$.

\section{Storage Conditions}

The spray-dried wine was stored in small opaque glass flasks in a constant temperature oven at $38{ }^{\circ} \mathrm{C}$, in the following conditions: a) in hermetically sealed flasks to preserve its initial moisture condition (aw 0.25), b) in open flasks placed over a saturated solution of magnesium chloride (aw 0.33 ). Temperature $38{ }^{\circ} \mathrm{C}$ is representative of accelerated shelf life [18]. Samples of both systems were periodically removed from storage and analyzed at selected times.

\section{Water activity and moisture content}

Water activity (aw) was measured using a dew point hygrometer Aqualab Series 3 (Decagon Devices, USA), previously calibrated against standard saturated salt solutions [19]. Moisture content was determined gravimetrically ( $1.5 \mathrm{~g}$ sample) using a forced convection constant temperature oven at 105 ${ }^{\circ} \mathrm{C}$ for 3 hours, then cooled for 1 hour in a glass desiccator and finally re-weighted to calculate water loss.

\section{Scanning electron microscopy (SEM)}

Morphological analysis was performed by SEM using a FEI, Quanta 200 microscope (Netherlands). The spray-dried red wine samples were placed in a carbon support and coated with a layer of gold (40$50 \mathrm{~nm}$ ) and examined using an acceleration voltage of $5 \mathrm{kV}$.

\section{Dry Extract}

Ten (10) g of each wine sample were carefully weighed in tared glass containers and dried in a constant temperature convection oven for 2 hours at $105^{\circ} \mathrm{C}$. Then, were cooled for 1 hour in a glass desiccator and re-weighted to calculate the dry extract content.

\section{Solubility}

One (1) $\mathrm{g}$ of wine powder was dissolved in $100 \mathrm{ml}$ of distilled water and mixed for $5 \mathrm{~min}$ in a magnetic stirrer. The solution was centrifuged at $3000 \mathrm{~g}$ for $5 \mathrm{~min}$ and $25 \mathrm{ml}$ of supernatant were transferred into tared glass containers. The samples were dried in a forced convection constant temperature oven for 5 hours at $105{ }^{\circ} \mathrm{C}$. The percentage of solubility was calculated according to AOAC [20]. 


\section{Total polyphenols}

Total polyphenols of the raw red wines and wine powders were determined by the Folin-Ciocalteau (FC) method [21,22]. All measurements were made in triplicate. Concentration was expressed as milligrams of gallic acid equivalents (GAE) per liter or per $100 \mathrm{~g}$ of powder.

\section{Total monomeric anthocyanin (TMA) by the $\mathrm{pH}$-differential method}

Monomeric anthocyanin content was measured following the method described by Giusti and Wrolstad [23]. Pigment content was expressed as malvidin-3-glucoside, where molar weight was $493.441 \mathrm{~g} / \mathrm{mol}$; molar absorptivity $\varepsilon=280001 / \mathrm{M} . \mathrm{cm}$; and path length of the cell $1 \mathrm{~cm}$. To express the TMA concentration in mg per g, the density of the diluted sample was taken into account.

\section{Sorption isotherms}

The equilibrium moisture of the wine powders was determined by means of the static gravimetric method [24]. For this purpose, $1.5 \mathrm{~g}$ samples of spray-dried wine powder were exposed at different saturated salt solutions that provide different values of relative humidity. The desiccators were placed in an oven at $30{ }^{\circ} \mathrm{C}$ and after reaching equilibrium the moisture content of the samples was determined using the gravimetric method. Each point of the different values of relative humidity was conducted three times.

\section{HPLC analysis of anthocyanins}

The chromatographic system employed was a Perkin-Elmer Series 200 high-performance liquid chromatograph equipped with a diode array detector, a quaternary pump, and an autosampler (HPLCDAD; PerkinElmer, Shelton, CT). Separation was performed on a reversed phase Chromolith Performance C18 column (100 mm x 4.6 mm I.D., $2 \mu \mathrm{m}$; Merck, Darmstadt, Germany) with a Chromolith guard cartridge $(10 \mathrm{~mm} \times 4.6 \mathrm{~mm})$ at $25{ }^{\circ} \mathrm{C}$. A gradient consisting of solvent A (water/formic acid, 90:10, v/v) and solvent B (acetonitrile) was applied at a flow rate of $1.1 \mathrm{ml} / \mathrm{min}$ from 0 to $22 \mathrm{~min}$ and $1.5 \mathrm{ml} / \mathrm{min}$ from 22 to $35 \mathrm{~min}$ as follows: $96-85 \% \mathrm{~A}$ and $4-15 \% \mathrm{~B}$ from 0 to 12 $\min , 85-85 \% \mathrm{~A}$ and $15-15 \% \mathrm{~B}$ from 12 to $22 \mathrm{~min}, 85-70 \% \mathrm{~A}$ and $15-30 \% \mathrm{~B}$ from 22 to $35 \mathrm{~min}$; followed by a final wash with $100 \%$ methanol and re-equilibration of the column. The samples were prepared by dissolving $40.0 \pm 0.5 \mathrm{mg}$ of wine powder in $1 \mathrm{ml}$ of hydroalcoholic solution (ethanol/water, $12: 88, \mathrm{v} / \mathrm{v}$ ) containing $5 \mathrm{~g} / \mathrm{L}$ of tartaric acid. Both, the powder solutions or wines were filtered through a $0.45 \mu \mathrm{m}$ pore size nylon membrane, and then $100 \mu \mathrm{l}$ was injected into the column. Diode array detection was performed from 210 to $600 \mathrm{~nm}$, and the quantification was carried out by peak area measurements at $520 \mathrm{~nm}$. The anthocyanin amount was calculated by using malvidin-3-glucoside chloride as is standard for a calibration curve $\left(\mathrm{R}^{2}=0.99\right)$. The results in wines were expressed as $\mathrm{mg} / \mathrm{L}$, and in powder solutions as mg per 100 grams of powder. Identification and confirmation of anthocyanin pigments were performed by HPLC-DAD/ESI-MS as described by Blanco Vega [25]. 


\section{Color determination}

Color measurements over time in the two $1 \%$ wine powder solutions $(\mathrm{pH} 3.0$ and $\mathrm{pH}$ 6.0) were evaluated using a MINOLTA CM-600d colorimeter (Konica-Minolta Orserver, Crop., USA), with the illuminant D65 and an observation angle of $2^{\circ}$. The measurement was made by placing $3 \mathrm{ml}$ of the two solutions prepared at the different time intervals of the test in plastic containers with a white background. The values of $\mathrm{L} *$ to $\mathrm{b} *$ (CIELab) were recorded directly from the equipment. All measurements were made in triplicate. Color difference $\left(\Delta \mathrm{E}^{*}{ }_{\mathrm{ab}}\right)$ was calculated as the euclidean distance between two points ( 1 and 2$)$ in three-dimensional $\left(\mathrm{L}^{*} \mathrm{a} * \mathrm{~b} *\right)$ space. $\Delta \mathrm{E}^{*}{ }_{\mathrm{ab}}\left(\mathrm{L}{ }_{1}, \mathrm{a}^{*}{ }_{1}, \mathrm{~b}^{*}{ }_{1} ; \mathrm{L}^{*}{ }_{2}, \mathrm{a}{ }_{2}, \mathrm{~b}{ }_{2}\right)$ $=\left[(\Delta \mathrm{L} *)^{2}+(\Delta \mathrm{a} *)^{2}+\left(\Delta \mathrm{b}^{*}\right)^{2}\right]^{1 / 2}$, where $\Delta \mathrm{L} *=\mathrm{L}^{*}{ }_{1}-\mathrm{L} *{ }_{2}, \Delta \mathrm{a} *=\mathrm{a}^{*}{ }_{1}-\mathrm{a}^{*}{ }_{2}$, and $\Delta \mathrm{b}^{*}=\mathrm{b}^{*}{ }_{1}-\mathrm{b}^{*}{ }_{2}$.

Influence of $\mathrm{pH}$, temperature and time on color and anthocyanins contents of the dissolve wine powder solution.

Two $1 \%$ solutions of wine powder were added with $5 \%(\mathrm{w} / \mathrm{w})$ sucrose, and $\mathrm{pH}$ was adjusted to two values $\mathrm{pH} 3.0$ and $\mathrm{pH}$ 6.0. The solutions were fractionated in test tubes ( $5 \mathrm{ml}$ of sample) and stored at $5{ }^{\circ} \mathrm{C}, 30{ }^{\circ} \mathrm{C}$ and $60{ }^{\circ} \mathrm{C}$ for different intervals of time. The color parameter $\left(\mathrm{L}^{*}, \mathrm{a}^{*}, \mathrm{~b}^{*}\right)$ and the concentration of malvidin-3-glucoside and total anthocyanin were determined at different times.

\section{Statistical Analyses}

All analyses were carried out in triplicate, and the statistical analysis was assessed with Statgraphics Centurion XVI software (StatPoint Technologies Inc., Warrenton, VA). All of the results of Table 3 were tested for homogeneity of variance using Cochran's test, and analyzed by one-way analysis of variance (ANOVA) and Tukey's honestly significant difference (HSD) test. A $p<0.05$ was considered to be statistically significant. 


\section{RESULTS AND DISCUSSION}

Table 1 show general analytical parameters of cv. Ancellotta. A simple way to highlight the coloring power of Ancellotta wine was by comparing its total anthocyanin to a red wine of a traditional varietal. For example, total anthocyanins value found in this work for Ancellota wine $(581 \mathrm{mg} / \mathrm{L})$ is dramatically higher than those reported by Fanzone et al. [26] for Cabernet sauvignon wines also from Mendoza area, which ranged between 105.5 and $158.7 \mathrm{mg} / \mathrm{L}$.

Table 1 General analytical parameters of cv. Ancellotta.

\begin{tabular}{|c|c|}
\hline Parameter & Ancellotta \\
\hline Dry extract $(\%, \mathrm{w} / \mathrm{w})$ & $3.15 \pm 0.04$ \\
\hline $\mathrm{pH}$ & $3.95 \pm 0.01$ \\
\hline TMA* $^{*}(\mathrm{mg}$ malvidin-3-glucoside/L) & $581 \pm 15$ \\
\hline Total polyphenols $(\mathrm{mg}$ gallic acid/L) & $3889 \pm 117$ \\
\hline
\end{tabular}

*TMA (Total monomeric anthocyanin by the pH-differential method)

Table 2 shows the characterization of Ancellotta wine powder obtained using maltodextrin $(13.5 \%$ $\mathrm{w} / \mathrm{w}$ ) and dried with $145^{\circ} \mathrm{C}$ inlet temperature and $70{ }^{\circ} \mathrm{C}$ outlet temperature (average).

Table 2 Characterization of Ancellotta powder obtained by spray-drying

\begin{tabular}{|c|c|}
\hline Parameter & Ancellotta \\
\hline TMA (mg malvidin-3-glucoside /100 g wine powder) & $348 \pm 10$ \\
\hline Total polyphenols (mg gallic acid/100 g wine powder) & $1958 \pm 286$ \\
\hline Water activity (aw) & $0.25 \pm 0.00$ \\
\hline Moisture (\% w/w) & $4.5 \pm 0.05$ \\
\hline Solubility (\%) & $99 \pm 0.20$ \\
\hline
\end{tabular}

*TMA (Total monomeric anthocyanin by the pH-differential method)

It is to be noted that percent yield in samples of Ancellotta spray-dried with MD10 averaged $59 \pm 3 \%$, which is similar to previous studies with Cabernet sauvignon wine [16]. The high solubility of the spray dried Ancellotta wine (Table 2) is one important parameter regarding its potential application in liquid matrices.

Fig 1 shows the visual color of liquid and spray dried Ancellota wine. The high anthocyanin content of the Ancellotta variety is reflected in its intense coloration. 


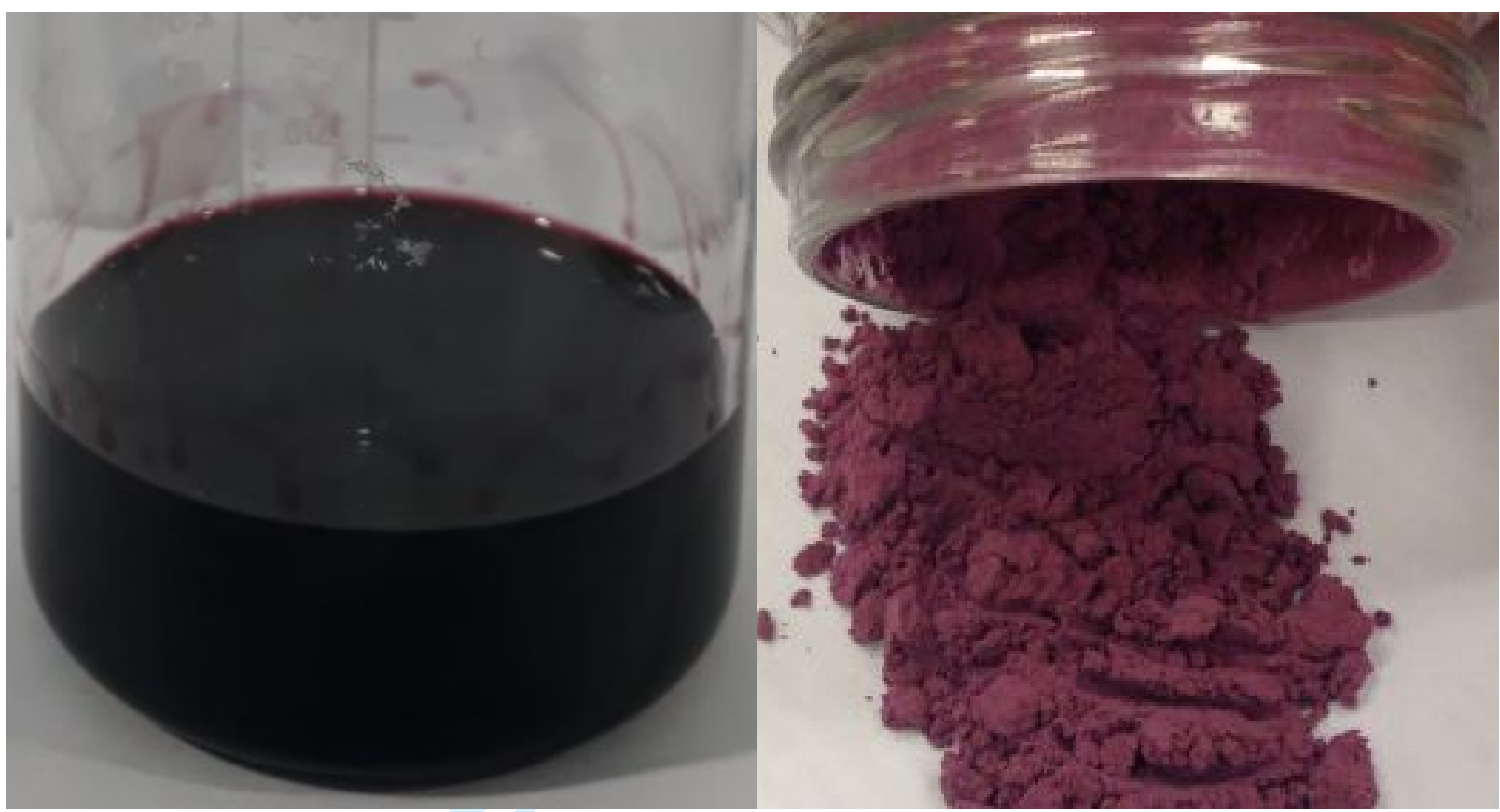

Fig 1 Visual color of Ancellotta wine and spray dried powder

Fig 2 shows scanning electron micrographs (SEM, x 10,000) of Ancellotta wine powder encapsulated with DE10 maltodextrin (dried at $145^{\circ} \mathrm{C}$ ).

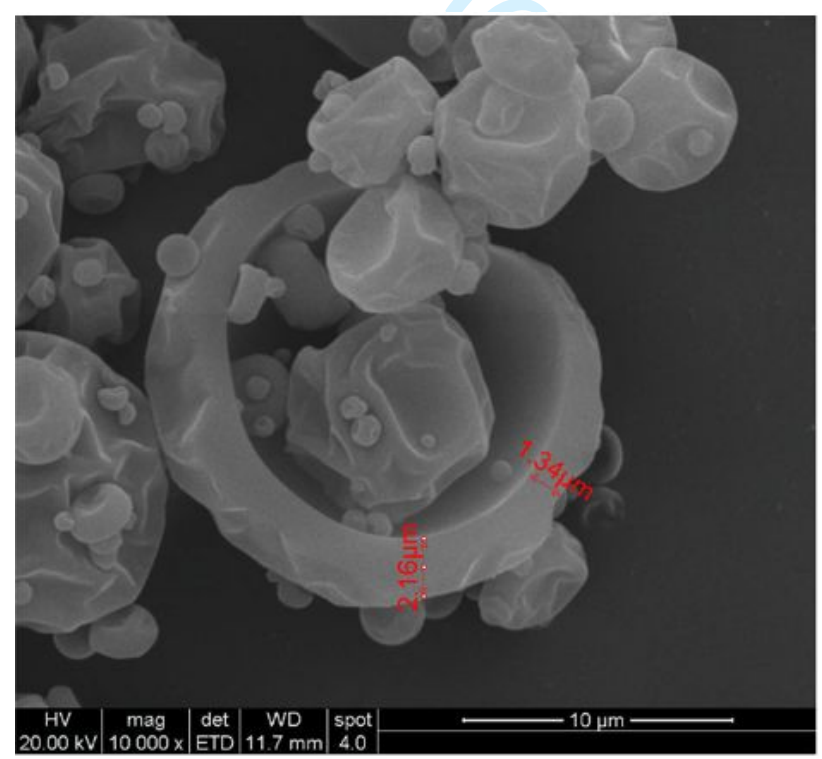

Fig 2 Scanning electron micrographs (SEM, x 10,000) of Ancellotta wine powder

During the spray-drying process of Ancellotta wine, the maltodextrin forms a layer on the surface of the drop, which can be seen in scanning electron micrographs (SEM) of the spray-dried Ancellotta wine (Fig 2). The SEM image show that maltodextrin enabled the formation of homogeneous capsules 
and polyphenols were encapsulated by the MD within a typical morphology for microcapsules. They visually appear a little dented with a rounded outer surface at x10,000 magnifications. The formation of these indentations on the surface (of particles obtained by spray-drying) is usually attributed to particle shrinkage due to the drastic loss of moisture followed by cooling $[27,28]$.

The anthocyanin profiles of the Ancellotta liquid wine and the powder were determined by HPLC-DAD and the results are shown in Table 3. The Ancellotta wine samples were analyzed within the same year of production. As mentioned before, it has high levels of anthocyanins and, consequently, the formation of derivatives is promoted during the winemaking processes. There is little literature about phenolic composition of the Ancellotta variety and its relationship with other international red varieties, while in Argentina there are no published data. However, some studies have shown higher levels of anthocyanins in this variety compared to other Italian cultivars [29-31]. In the present study, the mean proportions of different families in wine samples were $63.2 \%$ for glucosylated, $17.4 \%$ for acetylated, $8.1 \%$ for cinnamoylated, and $11.4 \%$ for pyranoanthocyanins and adducts (flavanol-anthocyanins) (Table 3).

Additionally, the mean values obtained for the ratios $\Sigma$ glucosylated/Lacetylated,

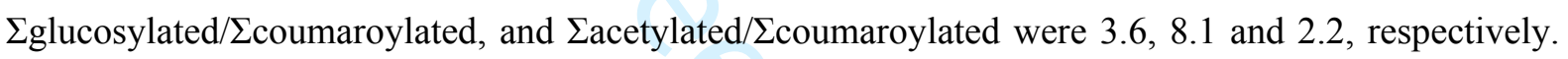
These results shown a pattern similar to that of Malbec, a red cultivar very important for Argentinian wine industry and characterized previously by Fanzone [32]. The effect of spray-drying, the ratio of the concentration (100 g of powder/100 $\mathrm{g}$ of liquid wine) was calculated for each anthocyanin. The ratio observed for each individual compound ranged between 4.1 and 17.9, with an average value of about 7.2. It is noticeable, that the cyanidin and malvidin derivatives were the most concentrate compounds, 10.2 and 7.2 fold, respectively, in relation to the rest of compounds. 
Table 3 Anthocyanins profile (HPLC-DAD) of Ancellotta liquid wine (mg /100 g) and wine powder $(\mathrm{mg} / 100 \mathrm{~g})$

\begin{tabular}{|c|c|c|c|c|}
\hline Compounds & $\begin{array}{c}\text { Ancellotta } 2015 \\
\text { liquid wine }\end{array}$ & & $\begin{array}{c}\text { Ancellotta } 2015 \\
\text { wine powder }\end{array}$ & \\
\hline Delphinidin-3-gluc oside & $7.55 \pm 0.73$ & $a$ & $35.97 \pm 2.34$ & $\mathrm{~b}$ \\
\hline Cyanidin-3-gluc oside & $1.24 \pm 0.12=$ & a & $6.96 \pm 0.45$ & b \\
\hline Petunidin-3-glucoside & $8.06 \pm 0.78$ & a & $39.10 \pm 2.55$ & b \\
\hline Peonidin-3-gluc oside & $3.94 \pm 0.38$ & a & $19.06 \pm 1.24$ & $\mathrm{~b}$ \\
\hline Malvidin-3-gluc oside & $20.64 \pm 2.00$ & a & $108.21 \pm 7.05$ & $\mathrm{~b}$ \\
\hline Total non-acylated & $41.43 \pm 4.00 \bar{a}$ & a & $209.30 \pm 13.64$ & $\mathrm{~b}$ \\
\hline Delphinidin-3-(6"-acetyl)-gluc oside & $2.62 \pm 0.25$ & a & $13.13 \pm 0.86$ & $\mathrm{~b}$ \\
\hline Cyanidin-3-(6"-acetyl)-glucoside & $0.91 \pm 0.09$ & a & $5.55 \pm 0.36$ & b \\
\hline Petunidin-3-(6"-acetyl)-glucoside & $2.50 \pm 0.24$ & a & $12.44 \pm 0.81$ & b \\
\hline Peonidin-3-(6"-acetyl)-glucoside & $0.74 \pm 0.07$ & a & $4.57 \pm 0.30$ & b \\
\hline Malvidin-3-(6"-acetyl)-gluc oside & $4.61 \pm 0.45$ & a & $22.78 \pm 1.48$ & $\mathrm{~b}$ \\
\hline Total acetylated & $11.38 \pm 1.10$ & $\mathrm{a}$ & $58.47 \pm 3.81$ & $\mathrm{~b}$ \\
\hline Delphinidin-3-(6"-p -coumaroyl)-gluc oside & $0.85 \pm 0.08$ & a & $5.05 \pm 0.33$ & b \\
\hline Cyanidin-3-(6"-p-coumaroyl)-glucoside & $0.13 \pm 0.01$ & a & $2.07 \pm 0.13$ & $\mathrm{~b}$ \\
\hline Petunidin-3-(6"-p-coumar oyl)-glucoside & $0.69 \pm 0.07$ & a & $3.44 \pm 0.22$ & $\mathrm{~b}$ \\
\hline Peonidin-3-(6"-p-coumaroyl)-glucoside & $0.82 \pm 0.08$ & a & $3.20 \pm 0.21$ & $\mathrm{~b}$ \\
\hline Malvidin-3-(6"-caffeoy I)-glucoside & $0.16 \pm 0.02=$ & a & $2.02 \pm 0.13$ & b \\
\hline Malvidin-3-(6"-p-coumaroyl)-glucoside & $2.64 \pm 0.26$ & a & $9.94 \pm 0.65$ & $\mathrm{~b}$ \\
\hline Total cinnamoylated & $5.28 \pm 0.51$ & $a$ & $25.73 \pm 1.68$ & $\mathrm{~b}$ \\
\hline 10-H-pyr anoma lvid in-3-(6"-acetyl)-glucoside & $0.82 \pm 0.08$ & $a$ & $5.52 \pm 0.36$ & $\mathrm{~b}$ \\
\hline 10-carboxy-pyr anodel phin idin-3-glucoside & $0.46 \pm 0.04=$ & a & $3.26 \pm 0.21$ & b \\
\hline 10-carboxy-pyr anopet unidin-3-glucoside & $0.74 \pm 0.07$ & a & $5.04 \pm 0.33$ & b \\
\hline 10-carboxy-pyr anopeonid in-3-glucoside & $0.60 \pm 0.06$ & a & $6.45 \pm 0.42$ & b \\
\hline 10-carboxy-pyr anomalvidin-3-glucoside & $1.11 \pm 0.11$ & a & $6.45 \pm 0.42$ & $\mathrm{~b}$ \\
\hline 10-carboxy-pyr anomalvid in-3-(6"-ac etyl)glucoside & $1.19 \pm 0.11=$ & a & $6.90 \pm 0.45$ & $\mathrm{~b}$ \\
\hline Total vit isin-like pyranoan thocyanins & $4.92 \pm 0.48 \quad \bar{a}$ & a & $33.62 \pm 2.19$ & $\mathrm{~b}$ \\
\hline 10-hydroxyphenyl-pyranomalvid in-3-glucoside & $0.36 \pm 0.04 \quad \bar{c}$ & a & $2.20 \pm 0.14$ & $\mathrm{~b}$ \\
\hline 10-hydroxyphenyl-pyranomalvid in-3-(6"-acetyl)-glucoside & $0.17 \pm 0.02$ & & ND & \\
\hline 10-hydroxyphenyl-pyranomalvid in-3-(6"-p-coumar oyl)-glucoside & $0.11 \pm 0.01$ & & ND & \\
\hline 10-methoxy-hydroxyphenyl-pyranomalvidin-3-glucoside & $0.23 \pm 0.02$ & & ND & \\
\hline Total hydroxyphenyl-pyranoanthocyanins & $0.87 \pm 0.08$ & a & $2.20 \pm 0.14$ & $\mathrm{~b}$ \\
\hline Malvidin-3-glucoside-catechin & $0.36 \pm 0.03 \approx$ & a & $3.58 \pm 0.23$ & b \\
\hline Malvidin-3-gluc oside-ethyl-catechin & $1.34 \pm 1.34 \quad \bar{c}$ & a & $7.13 \pm 0.46$ & \\
\hline Total fia vanol-anthocyanin adducts & $1.69 \pm 0.16$ & a & $10.71 \pm 0.70$ & $\mathrm{~b}$ \\
\hline Total anthocyanins & $65.57 \pm 6.34 \quad \bar{c}$ & a & $340.02 \pm 22.15$ & $\mathrm{~b}$ \\
\hline
\end{tabular}

The water sorption isotherm of Ancellotta powder at $30{ }^{\circ} \mathrm{C}$ is shown in Fig 3. Physical changes in the powder were observed with increasing the water activity level from aw 0.29 to aw 0.75 . At low water activity the powder remains free-flowing; at aw 0.43 the powder formed lumps and at aw 0.58 and above it completely collapses. This behavior can be explained by considering that physical changes in 
the amorphous wine powder matrix depends on time and are a function of ( $\mathrm{T}-\mathrm{Tg}$ ), where $\mathrm{T}$ is the storage temperature and $\mathrm{Tg}$ is the glass transition temperature [17]. Between water activity of aw 0.43 and aw 0.58 a small plateau was observed which could be attributed to crystallization of wine tartrates.

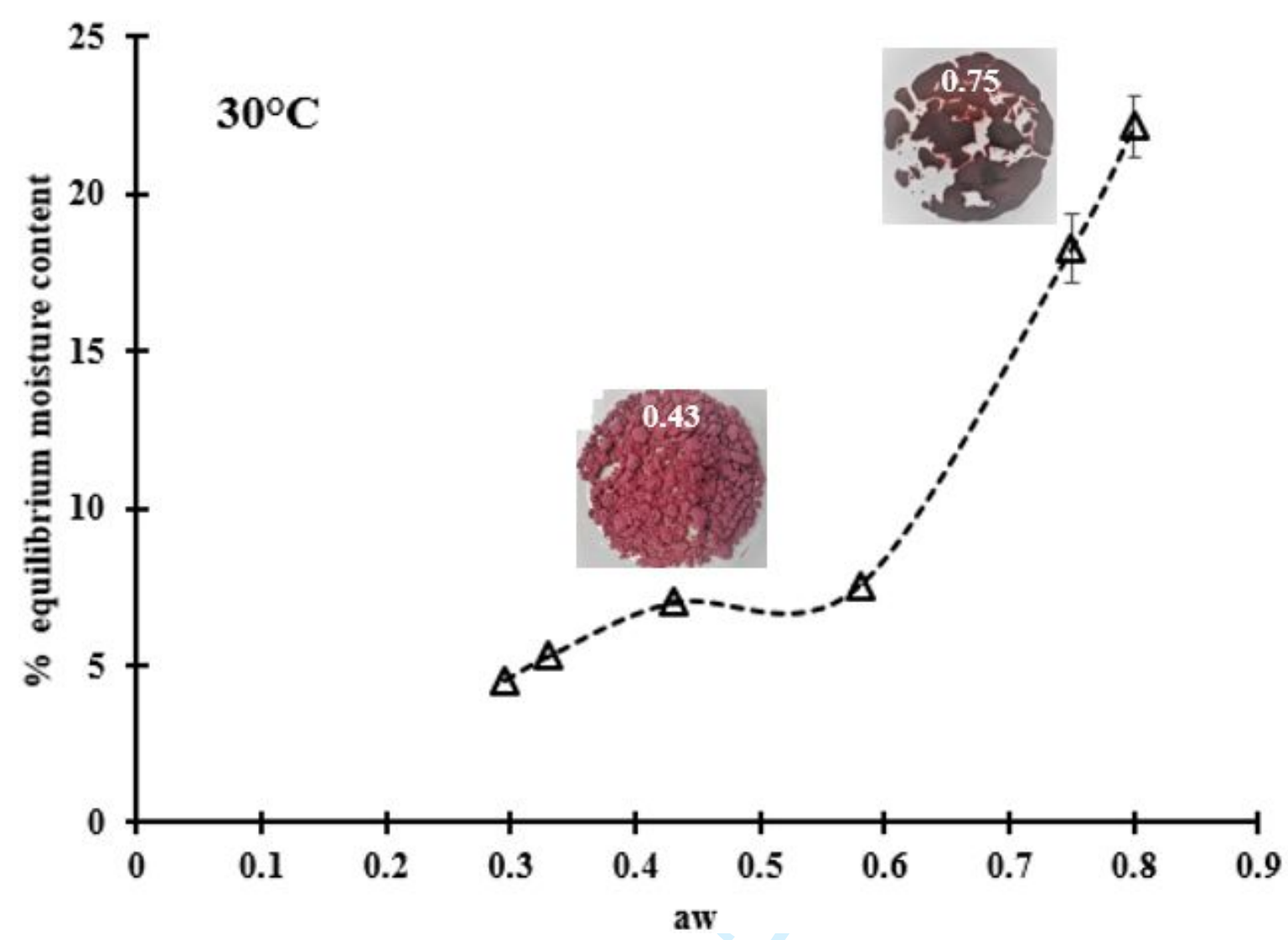

Fig 3 Adsorption isotherm at $30^{\circ} \mathrm{C}$ of Ancellotta wine powder. Error bars overlapped with some data points. A few pictures were inserted to show the physical changes associated with water activity

The stability of anthocyanins in Ancellotta wine powder during storage at $38^{\circ} \mathrm{C}$ and two different water activities (aw 0.25 and aw 0.33) was examined and results are presented in Fig 4. 


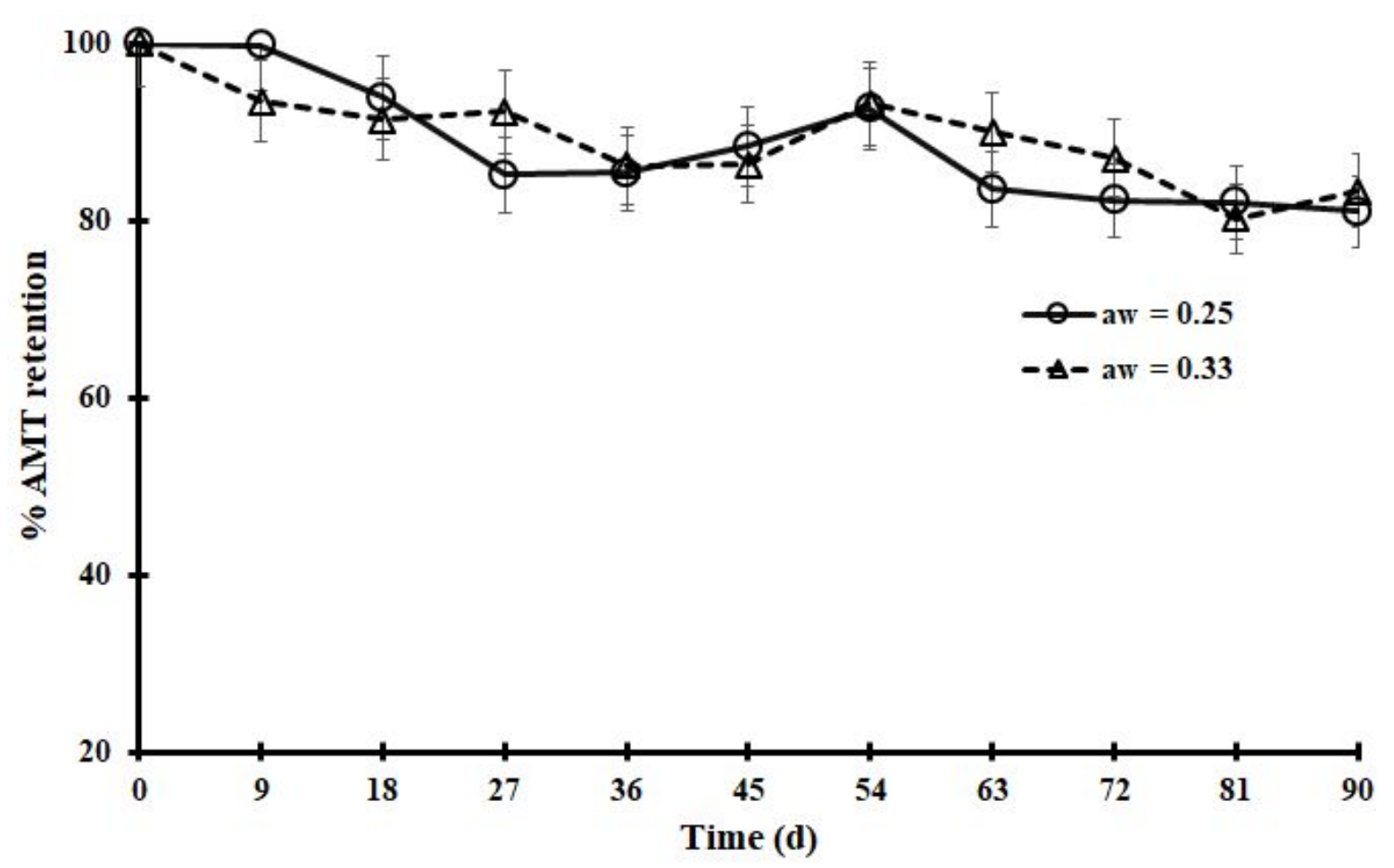

Fig 4 Stability of total monomeric anthocyanin (TMA) in spray-dried Ancellotta powder stored at 38 ${ }^{\circ} \mathrm{C}$ with two different values of water activity (aw 0.25 and aw 0.33 )

It is observed that after 90 days of storage at $38{ }^{\circ} \mathrm{C}$ the loss is only $20 \%$, as compared to the initial concentration. This behavior is consistent with previous literature results indicating that maintaining a low water activity value is critical for anthocyanin retention during storage [33].

The afforded mentioned behavior of total monomeric anthocyanins during storage was also examined by HPLC-DAD (in total anthocyanins and malvidin-3-glucoside contents) analysis and the results are shown in Fig 5. 


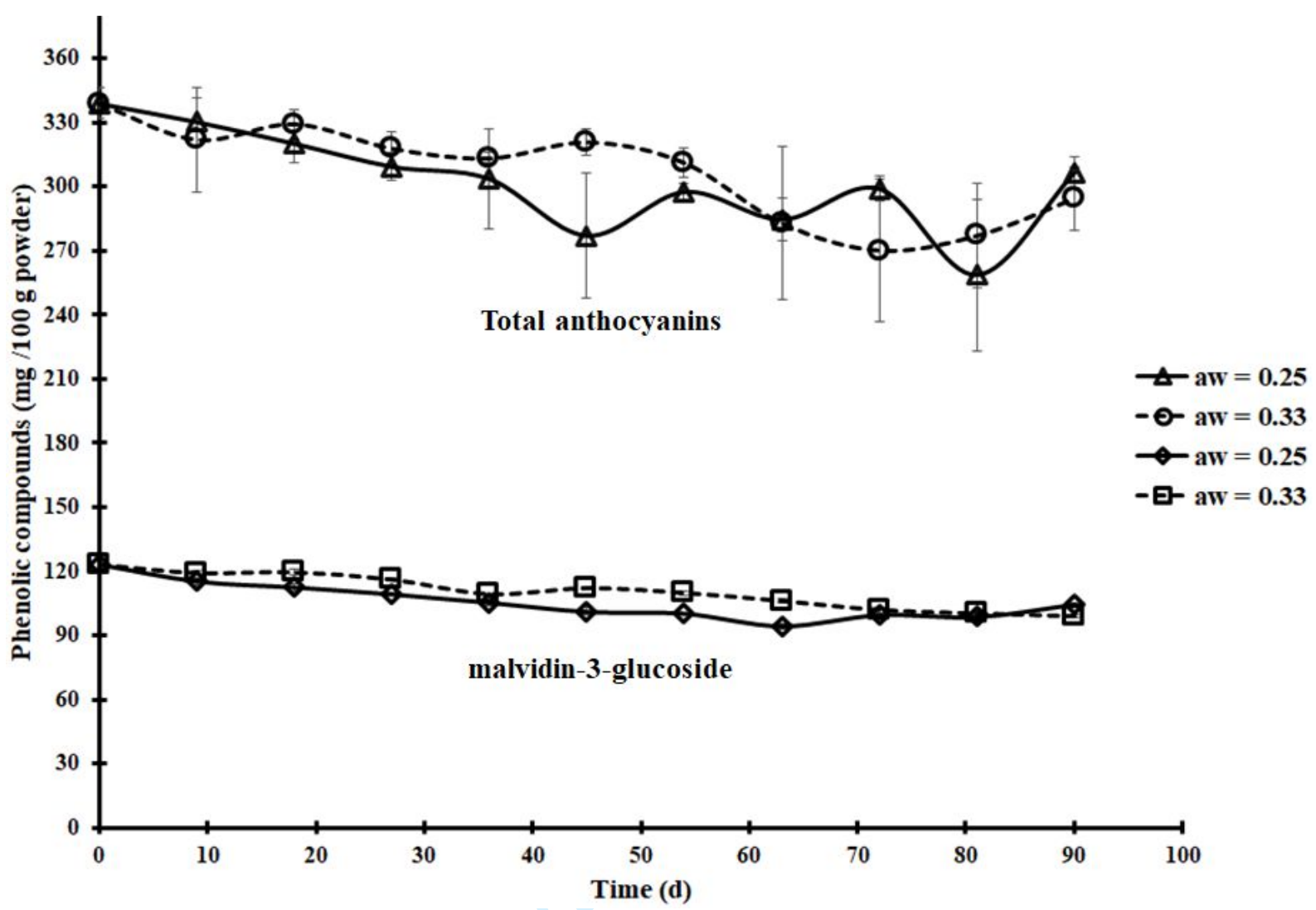

Fig 5 Stability of total anthocyanin and malvidin-3-glucoside in Ancellotta wine powder stored at 38 ${ }^{\circ} \mathrm{C}$ for two values of water activity (aw 0.25 and aw 0.33 ) determined by HPLC-DAD. Error bars overlapped with data points for malvidin-3-glucoside.

The behavior of malvidin-3-glucoside and total anthocyanins during storage at $38{ }^{\circ} \mathrm{C}$ and water activity aw 0.25 and aw 0.33 is fairly similar to that previously shown (Fig 4) using pH differential method. The total anthocyanins and malvidin-3-glucoside in the Ancellotta wine powder also decreased slightly with the time similarly to that observed with total monomeric anthocyanin.

The observed storage stability of total anthocyanins and malvidin-3-glucoside in the Ancellotta wine powder was associated with the protection afforded by powder matrix components; i.e. to act as a barrier to the permeation of detrimental substances like moisture and oxygen $[34,35]$.

The stability and equilibria of total anthocyanins and malvidin-3-glucoside in Ancellotta wine powder were also studied in aqueous solution at different $\mathrm{pH}$ values. As shown in Fig 6, the rate of total anthocyanins and malvidin-3-glucoside degradation increased up to its maximum value as temperature and $\mathrm{pH}$ increased from $5{ }^{\circ} \mathrm{C}$ to $60^{\circ} \mathrm{C}$ and $\mathrm{pH} 3.0$ to 6.0. It was observed that anthocyanin-containing in $1 \%$ wine powder solution displayed their most intense red coloration at acidic $\mathrm{pH} 3.0$ (data not shown), even holding a $1 \%$ wine powder solution at the acid $\mathrm{pH}$ values for a period as long as 47 hours, the red color of the solution retained its high stability at $5{ }^{\circ} \mathrm{C}$ and $30{ }^{\circ} \mathrm{C}$ (around $95 \%$ of retention at $5{ }^{\circ} \mathrm{C}$ and 
$50 \%$ of retention at $30^{\circ} \mathrm{C}$ to malvidin-3-glucoside and total anthocyanins respectively). With increasing $\mathrm{pH}$ value of the solution up to 6.0 , the red color greatly faded and almost appeared colorless even at a $\mathrm{pH}$ value of 3.0.

The stability of anthocyanins was markedly influenced by heat treatment and $\mathrm{pH}$. The highest levels of the degradation for total anthocyanins and malvidin-3-glucoside were observed at $\mathrm{pH} 6.0$ and $60{ }^{\circ} \mathrm{C}$ (90-100 \% degradation to malvidin-3-glucoside and total anthocyanins).
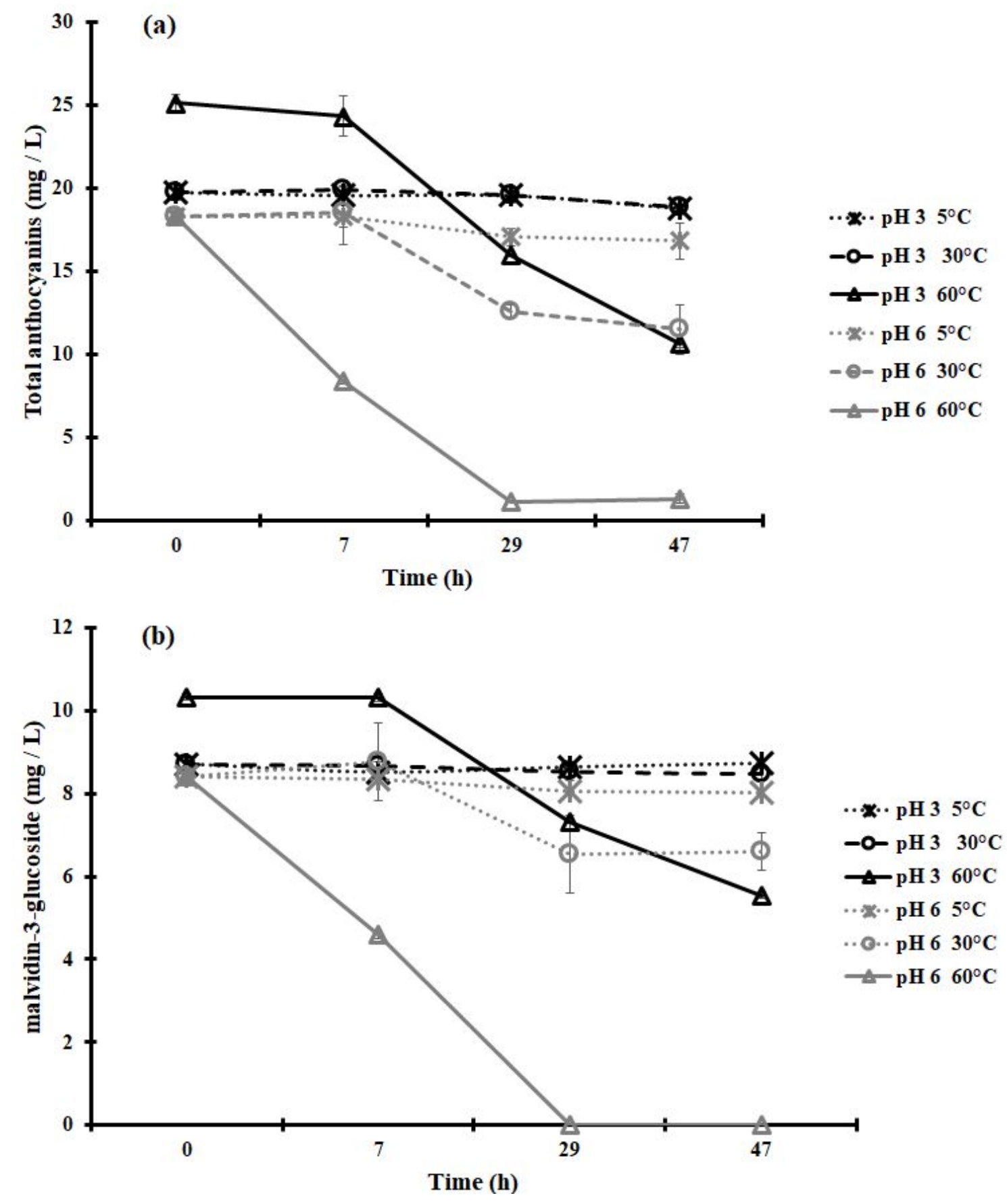

Fig 6 Stability of total anthocyanin (a) and malvidin-3-glucoside (b) in $1 \%$ wine powder solution containing $5 \%$ sucrose and stored 47 hours at $5{ }^{\circ} \mathrm{C}, 30{ }^{\circ} \mathrm{C}$ and $60{ }^{\circ} \mathrm{C}$ for $\mathrm{pH} 3.0$ and $\mathrm{pH} 6.0$. Error bars overlapped with some data points 


\section{Color behavior of anthocyanins as a potential colorant}

It is widely known that $\mathrm{pH}$ strongly influences the color of anthocyanins [36]. This effect was examined in a $1 \%$ wine powder solution in which $\mathrm{pH}$ was set at 3.0 and 6.0. Fig 7 shows the photographic record of color modification.

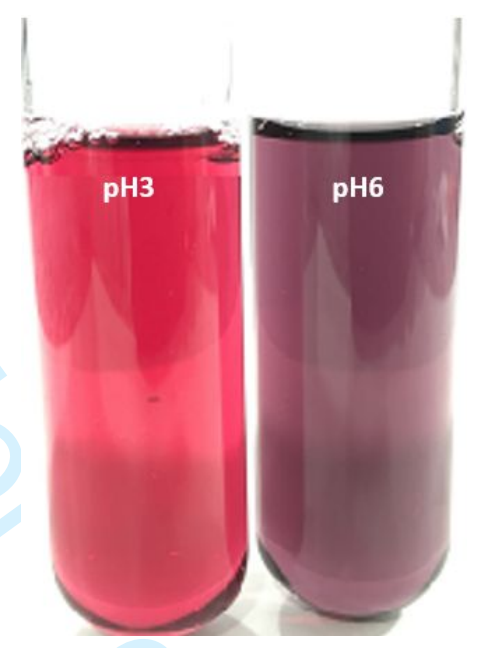

Fig 7 Effect of $\mathrm{pH}$ on visually color difference in $1 \%$ wine powder solution

Depending on the $\mathrm{pH}$ of the medium, the red-colored flavylium cation coexists as an equilibrium mixture with other forms of anthocyanins: the blue-purple quinonoidal bases, the colorless hemiacetal $\mathrm{B}$, and the pale yellow chalcones. Therefore, the same anthocyanin solution may show a different color. It is also known that at $\mathrm{pH} 3.0$ color is more stable than a higher $\mathrm{pH}[36,37]$.

As mentioned before, utilization of anthocyanins as food colorants have two main drawbacks: a) in aqueous medium anthocyanins undergo reversible structural transformations $\mathrm{pH}$ dependent, with concomitant change in color [8-10]; b) the thermal instability of anthocyanins during food processing and storage acts as an impediment to their use. These problems could be avoided using Ancellotta powder as a colorant, for example, in food powders having low water activity and $\mathrm{pH}$. For example, popular fruit drink powders are known to have $\mathrm{pH}$ close to 3.0 and water activity about aw $=0.30$ (unpublished results) which will protect anthocyanins.

In order to establish whether the observed changes in the CIELAB parameters were visually relevant, color variations between $1 \%$ wine powder solutions (containing $5 \%$ sucrose) at $\mathrm{pH} 3.0$ (a) and 6.0 (b), during storage at $5{ }^{\circ} \mathrm{C}, 30{ }^{\circ} \mathrm{C}$ and $60{ }^{\circ} \mathrm{C}$, were calculated and expressed as colorimetric differences $\Delta \mathrm{E}^{*}{ }_{\mathrm{ab}}$ (Fig 8). Moreover, the figure shows the relative contribution of Lightness, Chroma and Hue $\left(\Delta \mathrm{L}^{\prime}\right.$, $\left.\Delta \mathrm{C}^{\prime}, \Delta \mathrm{H}^{\prime}\right)$ to each color difference, what allows evaluating which color attribute was the most 
influenced. According to Martinez et al. [38], $\Delta \mathrm{E}^{*}{ }_{\mathrm{ab}}$ around 3 units indicates, the color differences detectable by the human eye (as an average observer). On this basis, the most perceptible color changes were produced when the $\mathrm{pH}$ and temperature were increased, observing the highest $\Delta \mathrm{E}^{*}$ ab values at 60 ${ }^{\circ} \mathrm{C}$ and $\mathrm{pH}$ 6.0, indicating greater color degradation (Fig 8b). This data is also in agreement with the aforementioned results for phenolic compounds and total monomeric anthocyanins. As can be seen in the Fig 8a, at pH 3.0 and $60{ }^{\circ} \mathrm{C}$ the main difference was qualitative, evidenced by the significantly higher contribution of hue $\% \Delta^{2} \mathrm{H}(87-93 \%)$, with respect to lightness $\% \Delta^{2} \mathrm{~L}$ or chroma $\% \Delta^{2} \mathrm{C}(1-12 \%$ and 1-6 \%, respectively). On the other hand, at pH 6.0 (Fig 8b) the quantitative color changes $\left(\% \Delta^{2} \mathrm{C}\right)$ became more pronounced, especially for range time $0-47$ hours, and a higher temperatures values. Between time-lapse 0-29 and 0-47 hours the chroma modifications $\% \Delta^{2} \mathrm{C}(52 \%$ in both range time) were particularly more marked than hue $\% \Delta^{2} \mathrm{H}(\approx 40 \%$ in both range time $)$ at $60{ }^{\circ} \mathrm{C}$. Therefore, a wine powder solution at $\mathrm{pH} 3.0$ and $\mathrm{pH} 6.0$ maintaining at $60^{\circ} \mathrm{C}$ promote a visual color change from brilliant red to more brownish hues. In contrast, samples kept at $5{ }^{\circ} \mathrm{C}$ maintained attractive colors even after 47 hours of storage. Cevallos-Casals and Cisneros-Zevallos [39] reported that after 41 hours in aqueous extracts of Andean purple corn and red-fleshed sweet potato, all quinonoidal structures decreased their absorbances significantly. The color of these unstable quinonoidal bases increasingly shifted towards brown and yellow with time. After 138 days, yellow colorless structures predominated for all extracts at $\mathrm{pH}>4.0$. Extracts at $\mathrm{pH} 1.0$ and 3.0 were selected, due to their higher stability as determined previously.

Sensory analysis will be carried out in future to confirm the viability of Ancellota powder as natural colorant in drinks powders. 

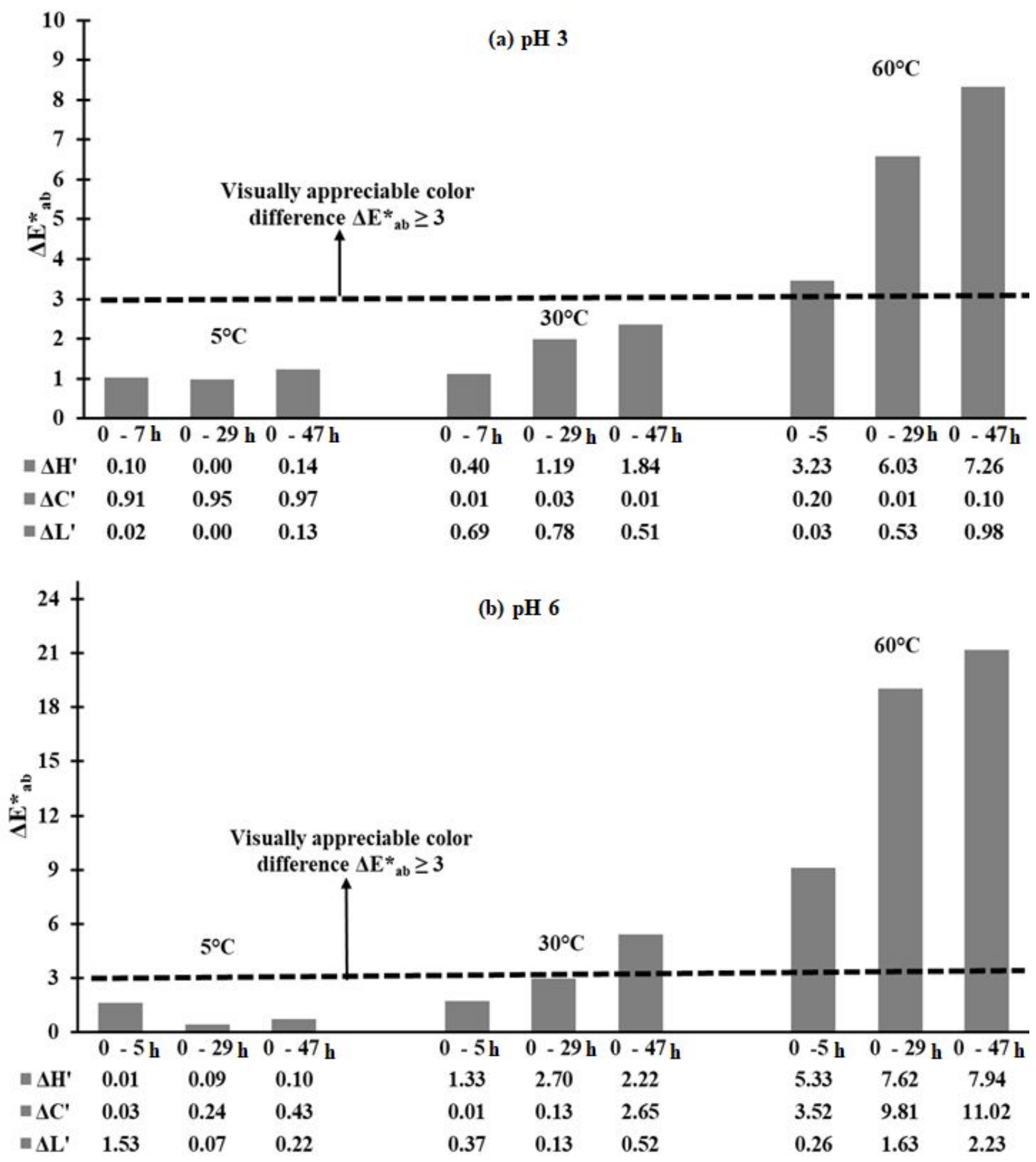

Fig 8 Color differences $\left(\Delta \mathrm{E}^{*}{ }_{\mathrm{ab}}\right)$, showing the relative contribution of Lightness, Chroma and Hue $\left(\Delta \mathrm{L}^{\prime}\right.$, $\left.\Delta \mathrm{C}^{\prime}, \Delta \mathrm{H}^{\prime}\right)$, in $1 \%$ wine powder solution containing $5 \%$ sucrose and $\mathrm{pH}$ values of $\mathrm{pH} 3.0$ (a) and $\mathrm{pH} 6.0$ (b) 


\section{Conclusions}

Ancellotta wine containing a fairly high amount of anthocyanins, was spray-dried with maltodextrin to obtain a free-flowing powder having an intense color. The stability of anthocyanin compounds (determinated by HPLC-DAD) in wine powder having water activity aw 0.33 or less was found to be remarkably good. Anthocyanins in $1 \%$ wine powder solution decreased with time in a temperaturedependent manner, with minimal loss at low temperature $\left(5^{\circ} \mathrm{C}\right)$ and higher loss at $60{ }^{\circ} \mathrm{C}$. Moreover, if $\mathrm{pH}$ of solution increased the anthocyanins decreased with time. It does appear that Ancellota powder could be used as a color of natural origin in products such as the popular "fruit drink powders", since they have a low water activity and a very favorable $\mathrm{pH}(3.0)$.

The present work is novel and provide important information about the feasibility of spray drying to encapsulate Ancellotta red wine in a maltodextrin matrix to use as natural food colorant. In addition to contain a high concentration of anthocyanins and other phenolic compounds, the wine powder maybe useful in preparation of healthy foods since it would contain the polyphenols of red wine, but without the presence of alcohol.

\section{Conflict of Interest}

The authors declare that they have no conflict of interest.

\section{Compliance with ethics requirements}

This article does not contain any studies with human or animal subjects. 


\section{References}

1. Griffiths J (2005) Coloring foods \& beverages. Food Technol 59(5): 38-44.

2. McCann D, Barrett A, Cooper A, Crumpler D, Dalen L, Grimshaw K, Kitchin E, Lok K, Porteous L, Prince E (2007) Food additives and hyperactive behaviour in 3-year-old and 8/9-year-old children in the community: a randomised, double-blinded, placebo-controlled trial. LANCET 370(9598): 1560-1567.

3. He J, Giusti MM (2010) Anthocyanins: natural colorants with health-promoting properties. Annu Rev Food Sci T 1: 163-187.

4. Heinonen J, Farahmandazad H, Vuorinen A, Kallio H, Yang B, Sainio T (2016) Extraction and purification of anthocyanins from purple-fleshed potato. Food Bioprod Process 99: 136-146.

5. Wang W, Jung J, Tomasino E, Zhao Y (2016) Optimization of solvent and ultrasound-assisted extraction for different anthocyanin rich fruit and their effects on anthocyanin compositions. LWT-Food Sci Technol 72: 229-238.

6. Ghosh D, Konishi T (2007) Anthocyanins and anthocyanin-rich extracts: role in diabetes and eye function. Asia Pac J Clin Nutr 16(2): 200-208.

7. Wang LS, Stoner GD (2008) Anthocyanins and their role in cancer prevention. Cancer Lett 269(2): 281-290.

8. Chandrasekhar J, Madhusudhan MC, Raghavarao KSMS (2012) Extraction of anthocyanins from red cabbage and purification using adsorption. Food Bioprod Process 90(4): 615-623.

9. Valls J, Millán S, Martí MP, Borràs E, Arola L (2009) Advanced separation methods of food anthocyanins, isoflavones and flavanols. J Chromatogr A 1216(43): 7143-7172.

10. Patil G, Madhusudhan MC, Babu BR, Raghavarao KSMS (2009) Extraction, dealcoholization and concentration of anthocyanin from red radish. Chem Eng Process 48(1): 364-369.

11. Stintzing FC, Carle R (2004) Functional properties of anthocyanins and betalains in plants, food, and in human nutrition. Trends Food Sci Tech 15(1): 19-38. 
12. Monagas M, Bartolomé B (2009) Anthocyanins and anthocyanin-derived compounds. In: Wine chemistry and biochemistry, 1st edn. Springer, New York, pp 439.

13. Informe de la variedad Ancellotta (2018). Departamento de Estadística y Estudios de Mercado, Subgerencia de Estadística y Asuntos Técnicos Internacionales, Instituto Nacional de Vitivinicultura (INV).

14. Masters K (1991) Spray drying handbook. Longman Scientific \& Technical; New York

15. Tonon RV, Brabet C, Hubinger MD (2010) Anthocyanin stability and antioxidant activity of spraydried açai (Euterpe oleracea Mart.) juice produced with different carrier agents. Food Res Int 43(3): 907-914.

16. Mahdavi SA, Jafari S M, Ghorbani M, Assadpoor E (2014) Spray-drying microencapsulation of anthocyanins by natural biopolymers: A review. Dry Technol 32(5):509-518.

17. Alvarez Gaona IJ, Bater C, Zamora MC, Chirife J (2017) Spray drying encapsulation of red wine: Stability of total monomeric anthocyanins and structural alterations upon storage. J Food Process Pres 42(2): e13457.

18. Labuza TP (1982) Shelf-life dating of foods. Food Nutr Press, Inc., Connecticut

19. Favetto G, Resnik S, Chirife J, Fontan CF (1983) Statistical evaluation of water activity measurements obtained with the Vaisala Humicap humidity meter. J Food Sci 48(2): 534-538.

20. AOAC (1995) Official methods of analysis. Arlington, USA.

21. Camussoni G, Carnevali E (2004) Determinación comparativa del contenido de polifenoles en vinos tintos de origen. In: Invenio 7 (13): 151-160.

22. Cioroi M, Musat CL (2007) Investigations on the correlations between polyphenol content from red wines and their antioxidant capacity. Cercetari Agronomice in Moldova 4: 35-42.

23. Giusti MM, Wrolstad RE (2001) Characterization and measurement of anthocyanins by UV-visible spectroscopy. Current Protocols in Food Analytical Chemistry 00: F1.2.1-F1.2.13. 
24. Iglesias HA, Chirife J (1976). Equilibrium moisture contents of air dried beef. Dependence on drying temperature. Int J Food Sci Tech 11(6): 565-573.

25. Blanco-Vega D, López-Bellido FJ, Alía-Robledo JM, Hermosín-Gutiérrez I (2011) HPLC-DADESI-MS/MS characterization of pyranoanthocyanins pigments formed in model wine. J Agr Food Chem 59(17): 9523-9531.

26. Fanzone M, Peña-Neira A, Gil M, Jofré V, Assof M, Zamora F (2012) Impact of phenolic and polysaccharidic composition on commercial value of Argentinean Malbec and Cabernet Sauvignon wines. Food Res Int 45(1): 402-414.

27. Saénz C, Tapia S, Chávez J, Robert P (2009) Microencapsulation by spray drying of bioactive compounds from cactus pear (Opuntia ficus-indica). Food Chem 114(2): 616-622.

28. Tonon RV (2009) Secagem por atomização do suco de açaí: influência das variáveis de processo, qualidade e estabilidade do produto. Ph.D. Thesis, Universidade Estadual de Campinas, Campinas, $28-29 \mathrm{p}$

29. Malinovski LI, Brighenti AF, Borghezan M, Guerra MP, Silva AL, Porro D, Vieira HJ (2016, August). Viticultural performance of Italian grapevines in high altitude regions of Santa Catarina State, Brazil. In Acta Hortic 1115: 203-210

30. Ragone R, Crupi P, Piccinonna S, Bergamini C, Mazzone F, Fanizzi FP, Schena FP, Antonacci D (2015). Classification and chemometric study of Southern Italy monovarietal wines based on NMR and HPLC-DAD-MS. Food Sci Biotechnol 24(3): 817-826.

31. Sartor S, Caliari V, Malinovski LI, Toaldo IM, Bordignon-Luiz MT (2017) Bioactive profiling of polyphenolics and oenological properties of red wines from Italian grapes (Vitis vinifera L.) cultivated in a selected subtropical region. Int J Food Prop 20(2): 1319-1328.

32. Fanzone M, Zamora F, Jofré V, Assof M, Gómez-Cordovés C, Peña-Neira Á (2012) Phenolic characterisation of red wines from different grape varieties cultivated in Mendoza province (Argentina). J Sci Food Agr 92(3): 704-718. 
33. Rocha-Parra DF, Lanari MC, Zamora MC, Chirife J (2016) Influence of storage conditions on phenolic compounds stability, antioxidant capacity and color of freeze-dried encapsulated red wine. LWT-Food Sci Technol 70: 162-170.

34. Wagner LA, Warthesen JJ (1995) Stability of spray-dried encapsulated carrot carotenes. J Food Sci 60(5): 1048-1053.

35. Serris GS, Biliaderis CG (2001) Degradation kinetic of beet root pigment encapsulated polymeric matrices. J Sci Food Agr 81: 691-700.

36. Heredia FJ, Francia-Aricha EM, Rivas-Gonzalo JC, Vicario IM, Santos-Buelga C (1998) Chromatic characterization of anthocyanins from red grapes-I. pH effect. Food Chem 63(4): 491-498.

37. Brouillard R (1982) Chemical structure of anthocyanins. In Anthocyanins as Food Colors. Academic Press, New York, pp 1-38.

38. Martínez JA, Melgosa M, Pérez MM, Hita E, Negueruela AI (2001) Note. Visual and instrumental color evaluation in red wines. Food Sci Technol Int 7(5): 439-444.

39. Cevallos-Casals BA, Cisneros-Zevallos L (2004) Stability of anthocyanin-based aqueous extracts of Andean purple corn and red-fleshed sweet potato compared to synthetic and natural colorants. Food Chem 86(1): 69-77. 


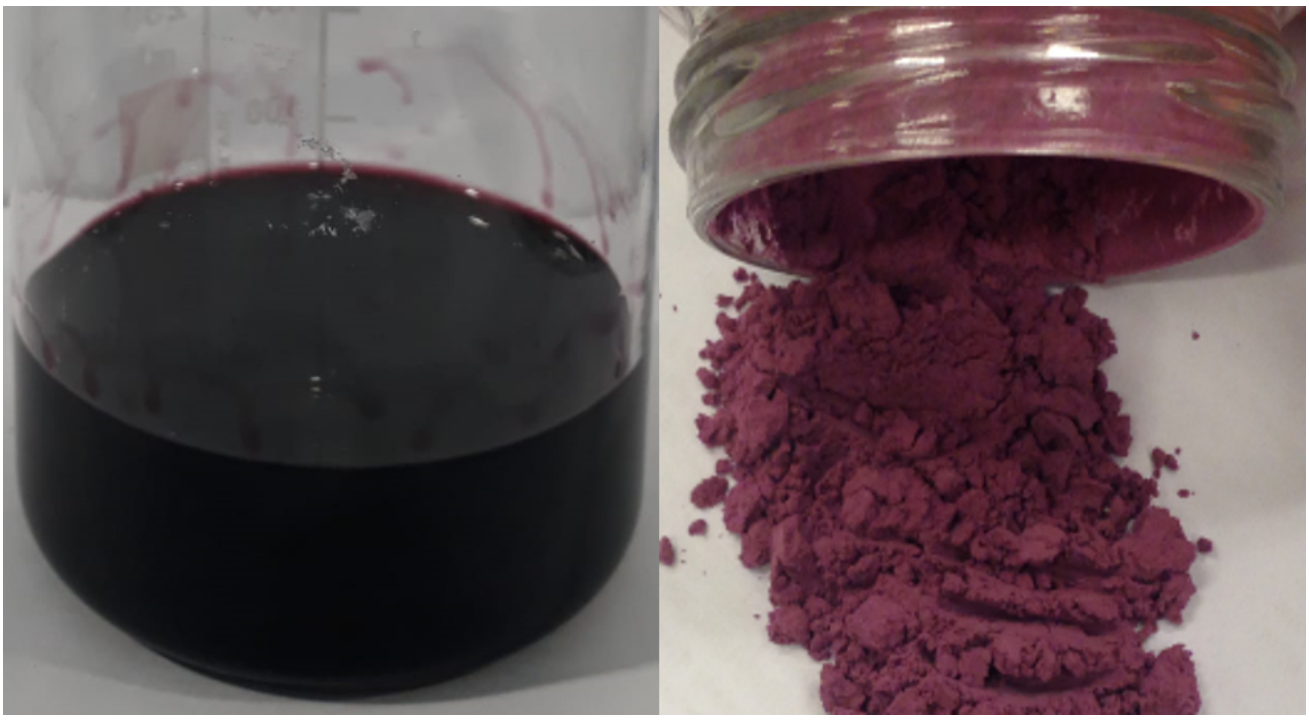

Fig 1 Visual color of Ancellotta wine and spray dried powder $167 \times 90 \mathrm{~mm}(150 \times 150 \mathrm{DPI})$ 
Fig 2 Scanning electron micrographs (SEM, x 10,000) of Ancellotta wine powder

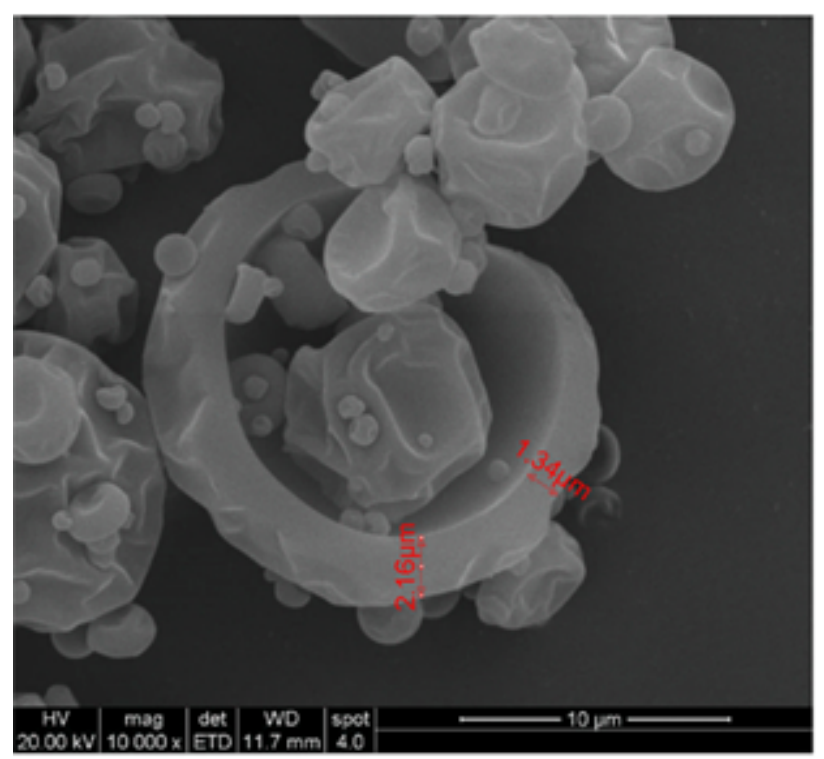

\section{$81 \times 75 \mathrm{~mm}(96 \times 96 \mathrm{DPI})$}

http://mc.manuscriptcentral.com/efrt 


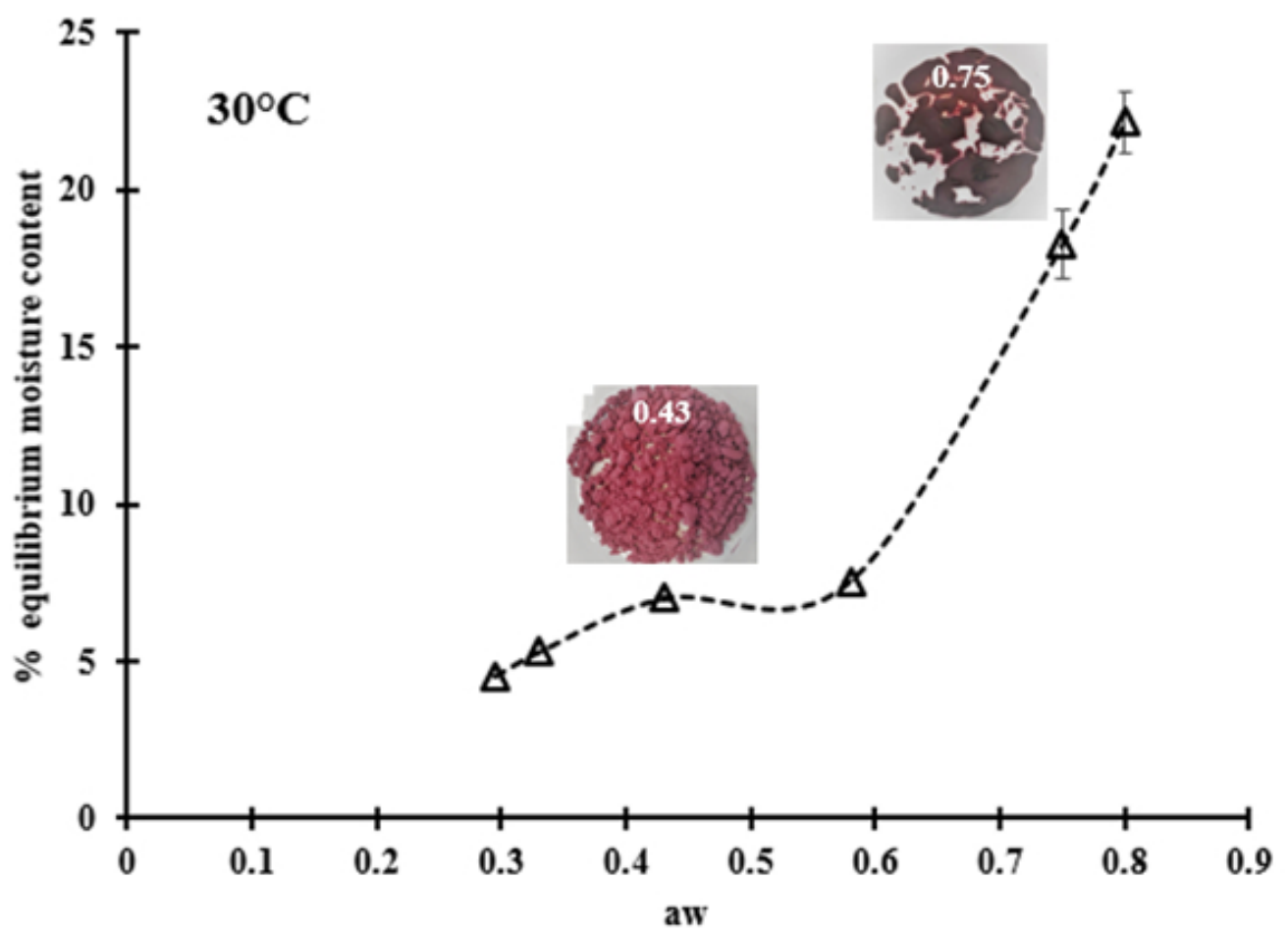

Fig 3 Adsorption isotherm at $30^{\circ} \mathrm{C}$ of Ancellotta wine powder. Error bars overlapped with some data points. A few pictures were inserted to show the physical changes associated with water activity

$154 \times 112 \mathrm{~mm}(96 \times 96 \mathrm{DPI})$ 
Fig 4 Stability of total monomeric anthocyanin (TMA) in spray-dried Ancellotta powder stored at $38^{\circ} \mathrm{C}$ with two different values of water activity (aw 0.25 and aw 0.33 )

$159 \times 97 \mathrm{~mm}(96 \times 96 \mathrm{DPI})$ 


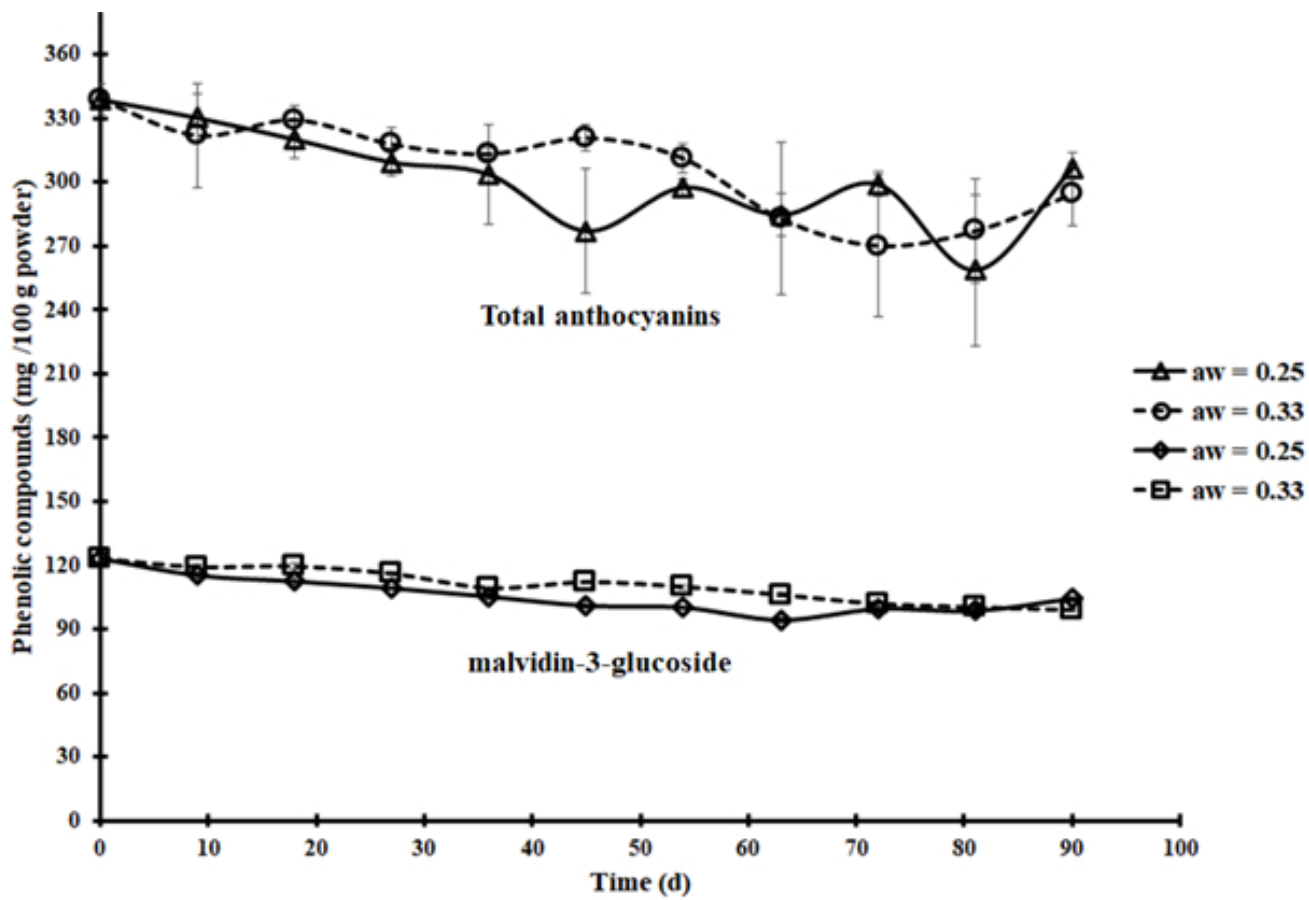

Fig 5 Stability of total anthocyanin and malvidin-3-glucoside in Ancellotta wine powder stored at $38^{\circ} \mathrm{C}$ for two values of water activity (aw 0.25 and aw 0.33 ) determined by HPLC-DAD. Error bars overlapped with data points for malvidin-3-glucoside.

$160 \times 109 \mathrm{~mm}(96 \times 96 \mathrm{DPI})$ 

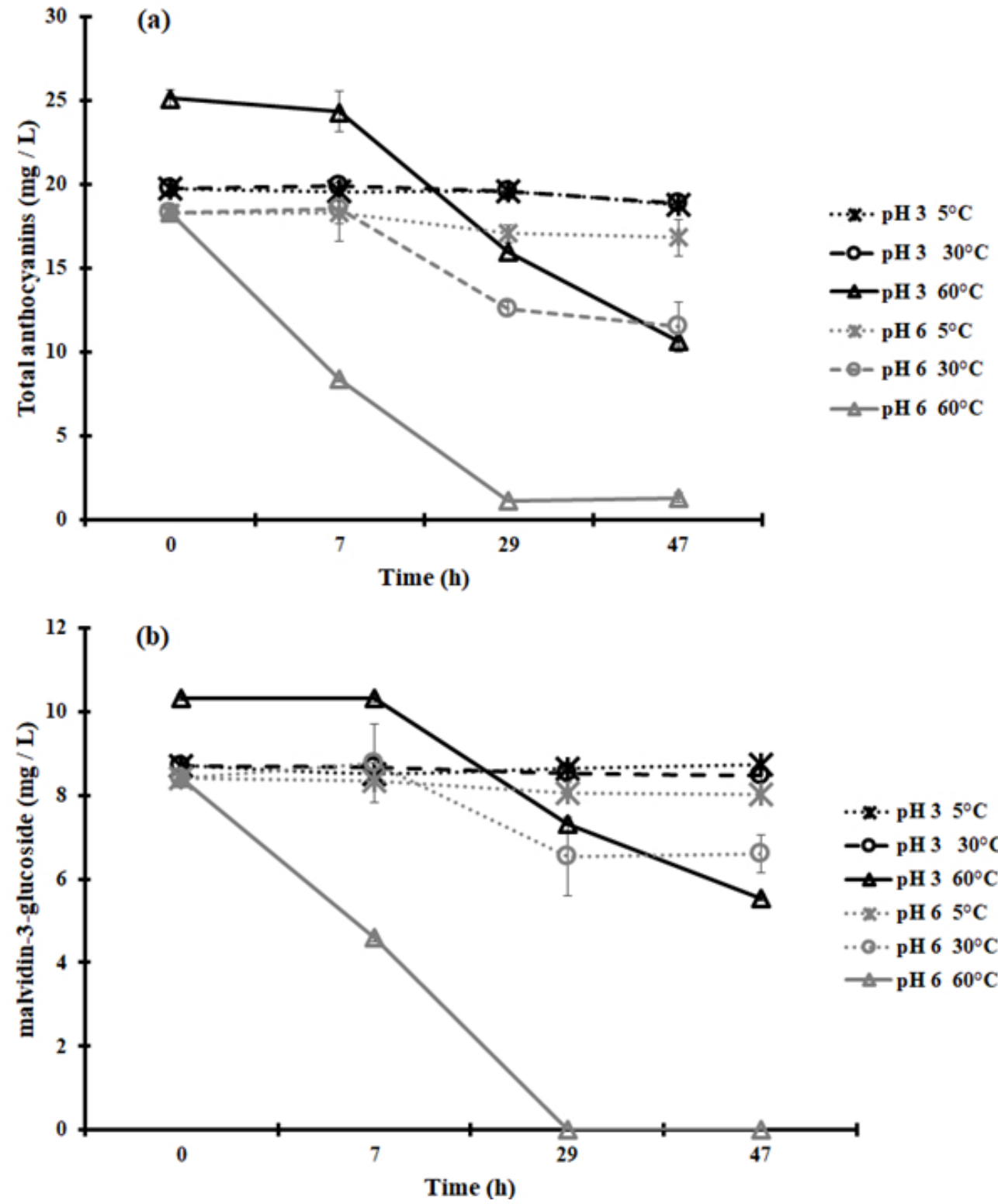

Fig 6 Stability of total anthocyanin (a) and malvidin-3-glucoside (b) in $1 \%$ wine powder solution containing $5 \%$ sucrose and stored 47 hours at $5^{\circ} \mathrm{C}, 30^{\circ} \mathrm{C}$ and $60^{\circ} \mathrm{C}$ for $\mathrm{pH} 3.0$ and $\mathrm{pH} 6.0$. Error bars overlapped with some data points

$159 \times 188 \mathrm{~mm}(96 \times 96 \mathrm{DPI})$ 


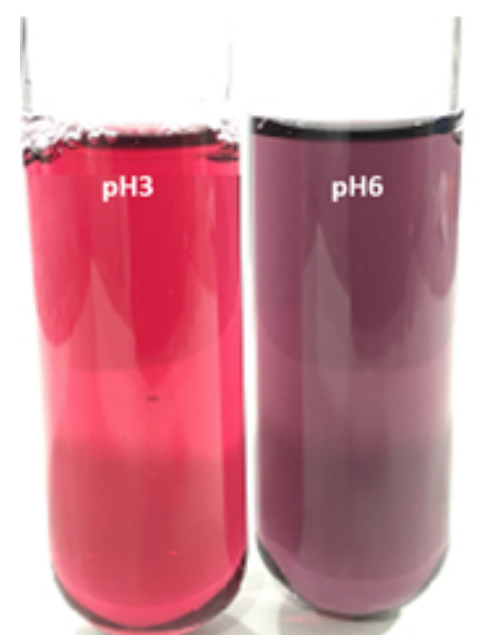

Fig 7 Effect of $\mathrm{pH}$ on visually color difference in $1 \%$ wine powder solution $48 \times 62 \mathrm{~mm}(96 \times 96 \mathrm{DPI})$ 

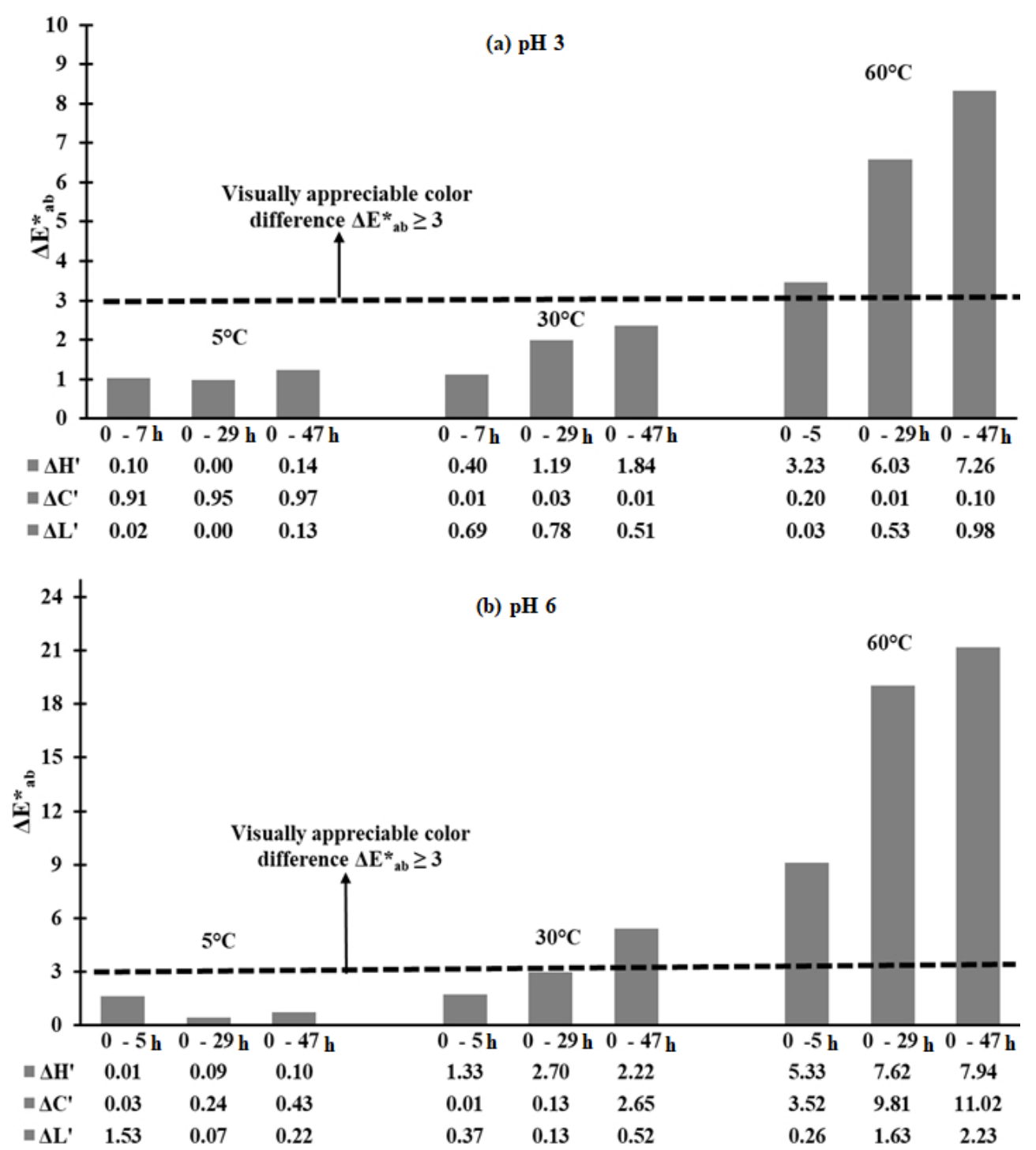

Fig 8 Color differences $\left(\Delta \mathrm{E}^{*} \mathrm{ab}\right)$, showing the relative contribution of Lightness, Chroma and Hue $\left(\Delta \mathrm{L}^{\prime}, \Delta \mathrm{C}^{\prime}\right.$, $\left.\Delta \mathrm{H}^{\prime}\right)$, in $1 \%$ wine powder solution containing $5 \%$ sucrose and $\mathrm{pH}$ values of $\mathrm{pH} 3.0$ (a) and $\mathrm{pH} 6.0$ (b)

$$
193 \times 212 \mathrm{~mm}(96 \times 96 \mathrm{DPI})
$$




\title{
"Spray-dried Ancellotta red wine: natural colorant with potential for food applications"
}

\author{
Izmari Jasel Alvarez Gaona (1) (2); Martín Fanzone (3); Santiago Sari (3); Mariela Assof (3); \\ Dolores Pérez ${ }^{(3)}$; Jorge Chirife ${ }^{(1)}$; María Clara Zamora ${ }^{(1)}(2)$
}

(1) Facultad de Ingeniería y Ciencias Agrarias, Pontificia Universidad Católica Argentina, Av. Alicia Moreau de Justo 1516-1560, C1107AFF CABA.

(2) Consejo Nacional de Investigaciones Científicas y Técnicas (CONICET), Godoy Cruz 2290, CABA, Argentina.

(3) Estación Experimental Agropecuaria Mendoza, Instituto Nacional de Tecnología Agropecuaria (EEA Mendoza INTA). San Martin 3853, (5507) Luján de Cuyo, Mendoza, Argentina.

Corresponding author:

izmarialvarez@uca.edu.ar

+5491150607367

ID 0000-0001-6411-729X

\section{Acknowledgments}

Authors acknowledge financial support from Facultad de Ingeniería y Ciencias Agrarias, Pontificia Universidad Católica Argentina. 
Keywords: Ancellotta; red wine; spray-drying; food colorant; anthocyanins.

\begin{abstract}
Ancellotta red wine (Vitis vinifera L.) was encapsulated by spray-drying (inlet and outlet temperatures were $145^{\circ} \mathrm{C}$ and $70^{\circ} \mathrm{C}$, respectively) to obtain a wine powder with a low water activity (aw) using maltodextrin DE10 as an encapsulating agent. The retention of Total Monomeric Anthocyanins (TMA) in the wine powder was found to be greater than $80 \%$. Anthocyanins profile of Ancellotta liquid wine and wine powder were characterized by using HPLC-DAD and thirty-three compounds were identified. The wine powder was stored under two different water activity values (aw 0.25 and aw 0.33 ). Furthermore, the TMA ( $\mathrm{pH}$ differential method), total anthocyanins and malvidin -3-glucoside were determined by HPLC-DAD for up to 90 days storage at $38{ }^{\circ} \mathrm{C}$. Total anthocyanins and malvidin-3glucoside decreased very slowly during storage. The stability of anthocyanins and color differences $\left(\Delta \mathrm{E}^{*}{ }_{\mathrm{ab}}\right)$ in $1 \%$ wine powder solution at different $\mathrm{pHs}$ and temperatures were evaluated. These results indicated that Ancellotta wine powder has the potential to be used as a food colorant in low $\mathrm{pH}$ and low water activity foods.
\end{abstract}




\section{INTRODUCTION}

It is common knowledge that humans are strongly influenced by color. In fact, color is the first notable characteristic of a food or a beverage and often predetermines the expectation of flavor and taste [1]. In recent years, there has been an increased awareness and interest around the potential impact of foods on health. For this reason, there is an increasing demand for natural ingredients in place of synthetic and/or artificial ingredients. As public concern about synthetic food colorants has increased, consumers and food manufacturers are looking for colorants from natural sources [2, 3].

Anthocyanins are natural pigments found in flowers, vegetables, fruits and foods. Examples can be seen in tea and wine with an extensive range of colors including red, blue and purple hues $[4,5]$. Anthocyanins are also beneficial to health as they act as antioxidants that scavenge free radicals and decrease the oxidative effect of the blood by donating protons to highly reactive radicals [4]. Research found that regular intake of anthocyanins may decrease the potential of contracting cancer, cardiac diseases, Alzheimer's disease, and diabetes $[3,6,7]$.

Due to the enormous potential of natural anthocyanins as healthy pigments, there is an increasing number of reports in the literature regarding their purification and separation from plant tissues $[4,8]$

Utilization of anthocyanins as food colorants have two main drawbacks: a) In aqueous medium such as foods, anthocyanins undergo reversible structural transformations that are $\mathrm{pH}$ dependent, with concomitant changes in color [8-10]; b) The thermal instability of anthocyanins during food processing and storage acts as an impediment to their use. For this reason, the anthocyanins are encapsulated to retain their color and improve stability [11].

It is well known that red wines have a significant amount of anthocyanins responsible for color [12], and cv. Ancellotta stands out among them for its extremely high concentration of anthocyanins. The red-skinned variety of Ancellotta is typically grown in North-West Italy. In Argentina, it is not a traditional variety, but it has gained great popularity in recent years, especially for wine blends, due to the above mentioned high concentration of anthocyanins.

Spray-drying is a technique used in the encapsulation of various bio-products. During the process, the "active" materials are trapped within a protective matrix of the encapsulating agent. This technique has been widely used for drying heat sensitive foods and pharmaceutical products [13], due to the rapid evaporation of water from the droplets formed $[14,15]$. Encapsulation plays a key role in maintaining the stability of bioactive compounds, therefore, improving their shelf life. 
Recently, Alvarez et al., [16] showed that a powder of red wine from cv. Cabernet sauvignon might be obtained by spray-drying leading to a free-flowing product with a good storage stability of anthocyanins, as long as the water activity of the powder remained low.

The objectives of the present study were to obtain a spray-dried encapsulated Ancellotta wine from Mendoza (Argentina) and evaluate its potential use as a colorant in food. The anthocyanins profile of the wine powder was evaluated using HPLC-DAD and the stability of the powder during storage was also monitored. Additionally, the color behavior of powder solutions at different $\mathrm{pH}$, temperatures, and times was evaluated. 


\section{MATERIALS AND METHODS}

\section{Reagents}

The encapsulating agent used for spray-drying was maltodextrin DE10 (Dextrose Equivalent 10-MD10) (Ingredion S.A, Argentina). The salts (analytical grade) used to control the relative humidity (RH \%) were magnesium chloride (33\%), potassium carbonate (43\%), sodium bromide (58\%), sodium chloride (75\%), and ammonium sulfate (80\%), purchased from Biopack (Argentina). The FolinCiocalteu reagent was obtained from Merck (Darmstadt, Germany). Standards of gallic acid [149-917] and malvidin-3-glucoside chloride [7228-78-6] were supplied by Sigma Aldrich (St. Louis, USA). Formic acid (98\%), chromatography grade methanol and acetonitrile were purchased from Merck (Darmstadt, Germany). All reactive chemicals were analytical grade or superior. Ultra-pure water was obtained from a RiO/Elix3-Sinergy185 purification system (Millipore, Sao Pablo, Brazil). Cellulose filters ( $3 \mu \mathrm{m}$ pore size) and $(0.45 \mu \mathrm{m}$ pore size) nylon membrane were supplied by Microclar (Buenos Aires, Argentina).

Red wines

Ancellotta experimental wine (2015 harvest) from La Consulta (Mendoza, Argentina), produced by Experimental Agricultural Station Mendoza, National Institute of Agricultural Technology (INTA), was used as a raw material $(\mathrm{pH} 3.95$, dry extract $3.15 \%(\mathrm{w} / \mathrm{w})$, alcohol $14.8 \%(\mathrm{v} / \mathrm{v})$, total acidity $5.3 \mathrm{~g}$ tartaric acid/L). For comparison, a commercial Cabernet sauvignon wine (2015 harvest), Neuquén (Argentina) was used; $\mathrm{pH} 3.74$, dry extract was $2.27 \%(\mathrm{w} / \mathrm{w})$, alcohol $14.1 \%(\mathrm{v} / \mathrm{v})$.

\section{Spray-drying}

A mixture of $13.5 \%(\mathrm{w} / \mathrm{w})$ maltodextrin DE10 and $86.5 \%(\mathrm{w} / \mathrm{w})$ red wine was prepared and resulting solution was spray-dried with a mini spray dryer Buchi model B-290 (Büchi Laboratoriums Technik, Switzerland), under the following operating conditions: feed flow rate $600 \mathrm{~g} / \mathrm{h}$; drying air inlet temperature $145{ }^{\circ} \mathrm{C}$, and outlet temperature (average) $70{ }^{\circ} \mathrm{C}$; flow meter spraying air (rotameter) 30 $\mathrm{mm}$; 0.23 bar pressure drop; and $439 \mathrm{~L} / \mathrm{h}$ actual volume flow (at standard temperature and pressure). The yield of spray-drying was $59 \pm 3 \%$.

\section{Storage Conditions}

The spray-dried wine was stored in small opaque glass flasks in a constant temperature oven at $38^{\circ} \mathrm{C}$, in the following conditions: a) in hermetically sealed flasks to preserve its initial moisture condition (aw 0.25), b) in open flasks placed over a saturated solution of magnesium chloride (aw 0.33). Temperature $38{ }^{\circ} \mathrm{C}$ is representative of accelerated shelf life [17]. Samples of both systems were periodically removed from storage and analyzed at selected times. 


\section{Water activity and moisture content}

Water activity (aw) was measured using a dew point hygrometer Aqualab Series 3 (Decagon Devices, USA), previously calibrated against standard saturated salt solutions [18]. Moisture content was determined gravimetrically ( $1.5 \mathrm{~g}$ sample) using a forced convection constant temperature oven at 105 ${ }^{\circ} \mathrm{C}$ for 3 hours, then cooled for 1 hour in a glass desiccator and finally re-weighted to calculate water loss.

\section{Scanning electron microscopy (SEM)}

Morphological analysis was performed by SEM using a FEI, Quanta 200 microscope (Netherlands). The spray-dried red wine samples were placed in a carbon support and coated with a layer of gold (40$50 \mathrm{~nm}$ ) and examined using an acceleration voltage of $5 \mathrm{kV}$.

\section{Dry Extract}

Ten (10) g of each wine sample were carefully weighed in tared glass containers and dried in a constant temperature convection oven for 2 hours at $105^{\circ} \mathrm{C}$. Then, were cooled for 1 hour in a glass desiccator and re-weighted to calculate the dry extract content.

\section{Solubility}

One (1) $\mathrm{g}$ of wine powder was dissolved in $100 \mathrm{ml}$ of distilled water and mixed for $5 \mathrm{~min}$ in a magnetic stirrer. The solution was centrifuged at $3000 \mathrm{~g}$ for $5 \mathrm{~min}$ and $25 \mathrm{ml}$ of supernatant were transferred into tared glass containers. The samples were dried in a forced convection constant temperature oven for 5 hours at $105^{\circ} \mathrm{C}$. The percentage of solubility was calculated according to AOAC [19].

\section{Total polyphenols}

Total polyphenols of the raw red wines and wine powders were determined by the Folin-Ciocalteau (FC) method [20, 21]. All measurements were made in triplicate. Concentration was expressed as milligrams of gallic acid equivalents (GAE) per liter or per $100 \mathrm{~g}$ of powder.

\section{Total monomeric anthocyanin (TMA) by the $\mathrm{pH}$-differential method}

Monomeric anthocyanin content was measured following the method described by Giusti and Wrolstad [22]. Pigment content was expressed as malvidin-3-glucoside, where molar weight was $493.441 \mathrm{~g} / \mathrm{mol}$; molar absorptivity $\varepsilon=280001 / \mathrm{M} . \mathrm{cm}$; and path length of the cell $1 \mathrm{~cm}$. To express the TMA concentration in mg per $g$, the density of the diluted sample was taken into account. 


\section{Sorption isotherms}

The equilibrium moisture of the wine powders was determined by means of the static gravimetric method [23]. For this purpose, $1.5 \mathrm{~g}$ samples of spray-dried wine powder were exposed at different saturated salt solutions that provide different values of relative humidity. The desiccators were placed in an oven at $30^{\circ} \mathrm{C}$ and after reaching equilibrium the moisture content of the samples was determined using the gravimetric method. Each point of the different values of relative humidity was conducted three times.

\section{HPLC analysis of anthocyanins}

The chromatographic system employed was a Perkin-Elmer Series 200 high-performance liquid chromatograph equipped with a diode array detector, a quaternary pump, and an autosampler (HPLCDAD; PerkinElmer, Shelton, CT). Separation was performed on a reversed phase Chromolith Performance C18 column (100 mm x 4.6 mm I.D., $2 \mu \mathrm{m}$; Merck, Darmstadt, Germany) with a Chromolith guard cartridge $(10 \mathrm{~mm} \times 4.6 \mathrm{~mm})$ at $25{ }^{\circ} \mathrm{C}$. A gradient consisting of solvent A (water/formic acid, 90:10, v/v) and solvent B (acetonitrile) was applied at a flow rate of $1.1 \mathrm{ml} / \mathrm{min}$ from 0 to $22 \mathrm{~min}$ and $1.5 \mathrm{ml} / \mathrm{min}$ from 22 to $35 \mathrm{~min}$ as follows: $96-85 \% \mathrm{~A}$ and $4-15 \% \mathrm{~B}$ from 0 to 12 $\min , 85-85 \% \mathrm{~A}$ and $15-15 \% \mathrm{~B}$ from 12 to $22 \mathrm{~min}, 85-70 \% \mathrm{~A}$ and $15-30 \% \mathrm{~B}$ from 22 to $35 \mathrm{~min}$; followed by a final wash with $100 \%$ methanol and re-equilibration of the column. The samples were prepared by dissolving $40.0 \pm 0.5 \mathrm{mg}$ of wine powder in $1 \mathrm{ml}$ of hydroalcoholic solution (ethanol/water, $12: 88, \mathrm{v} / \mathrm{v}$ ) containing $5 \mathrm{~g} / \mathrm{L}$ of tartaric acid. Both, the powder solutions or wines were filtered through a $0.45 \mu \mathrm{m}$ pore size nylon membrane, and then $100 \mu \mathrm{l}$ was injected into the column. Diode array detection was performed from 210 to $600 \mathrm{~nm}$, and the quantification was carried out by peak area measurements at $520 \mathrm{~nm}$. The anthocyanin amount was calculated by using malvidin-3-glucoside chloride as is standard for a calibration curve $\left(\mathrm{R}^{2}=0.99\right)$. The results in wines were expressed as $\mathrm{mg} / \mathrm{L}$, and in powder solutions as mg per 100 grams of powder. Identification and confirmation of anthocyanin pigments were performed by HPLC-DAD/ESI-MS as described by Blanco Vega [24].

\section{Color determination}

Color measurements over time in the two $1 \%$ wine powder solutions $(\mathrm{pH} 3.0$ and $\mathrm{pH}$ 6.0) were evaluated using a MINOLTA CM-600d colorimeter (Konica-Minolta Orserver, Crop., USA), with the illuminant D65 and an observation angle of $2^{\circ}$. The measurement was made by placing $3 \mathrm{ml}$ of the two solutions prepared at the different time intervals of the test in plastic containers with a white background. The values of $\mathrm{L} *$ to $\mathrm{b} *$ (CIELab) were recorded directly from the equipment. All measurements were made in triplicate. Color difference $\left(\Delta \mathrm{E}^{*}{ }_{\mathrm{ab}}\right)$ was calculated as the euclidean distance between two points (1 and 2) in three-dimensional ( $\left.\mathrm{L}^{*} \mathrm{a}^{*} \mathrm{~b} *\right)$ space. $\Delta \mathrm{E}^{*}{ }_{\mathrm{ab}}\left(\mathrm{L}^{*}{ }_{1}, \mathrm{a}^{*}{ }_{1}, \mathrm{~b}^{*}{ }_{1} ; \mathrm{L}^{*}, \mathrm{a}^{*}{ }_{2}, \mathrm{~b}^{*}{ }_{2}\right)$ $=\left[\left(\Delta \mathrm{L}^{*}\right)^{2}+(\Delta \mathrm{a} *)^{2}+\left(\Delta \mathrm{b}^{*}\right)^{2}\right]^{1 / 2}$, where $\Delta \mathrm{L} *=\mathrm{L}^{*}{ }_{1}-\mathrm{L}^{*}{ }_{2}, \Delta \mathrm{a} *=\mathrm{a}^{*}{ }_{1}-\mathrm{a}^{*}{ }_{2}$, and $\Delta \mathrm{b}^{*}=\mathrm{b}^{*}{ }_{1}-\mathrm{b}^{*}{ }_{2}$. 
Influence of $\mathrm{pH}$, temperature and time on color and anthocyanins contents of the dissolve wine powder solution.

Two $1 \%$ solutions of wine powder were added with $5 \%(\mathrm{w} / \mathrm{w})$ sucrose, and $\mathrm{pH}$ was adjusted to two values $\mathrm{pH} 3.0$ and $\mathrm{pH}$ 6.0. The solutions were fractionated in test tubes ( $5 \mathrm{ml}$ of sample) and stored at $5{ }^{\circ} \mathrm{C}, 30{ }^{\circ} \mathrm{C}$ and $60{ }^{\circ} \mathrm{C}$ for different intervals of time. The color parameter $\left(\mathrm{L}^{*}, \mathrm{a}^{*}, \mathrm{~b}^{*}\right)$ and the concentration of malvidin-3-glucoside and total anthocyanin were determined at different times. 


\section{RESULTS AND DISCUSSION}

A simple way to highlight the coloring power of Ancellotta wine was by comparing it to a red wine of a traditional varietal. Table 1 compares overall composition of cv. Ancellotta and cv. Cabernet sauvignon (harvest 2015). It is remarkable that the concentration of total monomeric anthocyanins is 3.5 times higher in the Ancellotta wine than in the C. sauvignon.

Table 1 Comparison of overall composition of red wines from cvs. Cabernet sauvignon and Ancellotta (harvest 2015)

\begin{tabular}{|l|c|c|}
\hline \multicolumn{1}{|c|}{ Parameter } & Cabernet sauvignon & Ancellotta \\
\hline Dry extract $(\%, w / w)$ & $2.27^{* *} \pm 0.03$ & $3.15 \pm 0.04$ \\
\hline pH & $3.74 \pm 0.01$ & $3.95 \pm 0.01$ \\
\hline TMA* $($ mg malvidin-3-glucoside/L) & $159 \pm 7^{\mathrm{a}}$ & $581 \pm 15^{\mathrm{b}}$ \\
\hline Total polyphenols (mg gallic acid/L) & $2076 \pm 56^{\mathrm{a}}$ & $3889 \pm 117^{\mathrm{b}}$ \\
\hline
\end{tabular}

*TMA (Total monomeric anthocyanin by the pH-differential method)

**Means $\pm \mathrm{SD}(\mathrm{n}=3)$. Different letters in the same row indicate significant differences $(\mathrm{p}<0.05$, Tukey HSD Test, $\alpha=0.05)$.

The same comparison (Table 1), but using spray-dried powders was performed. Table 2 shows the characterization of Ancellotta wine powder and Cabernet sauvignon wine powder using maltodextrin $(13.5 \% \mathrm{w} / \mathrm{w})$ and inlet temperature $145^{\circ} \mathrm{C}$ and outlet temperature average $70{ }^{\circ} \mathrm{C}$.

Table 2 Characterization of Cabernet sauvignon and Ancellotta powders obtained by spray-drying

\begin{tabular}{|l|c|c|}
\hline \multicolumn{1}{|c|}{ Parameter } & Cabernet sauvignon & Ancellotta \\
\hline TMA (mg malvidin-3-glucoside /100 g wine powder) & $100^{*} \pm 2^{\mathrm{a}}$ & $348 \pm 10^{\mathrm{b}}$ \\
\hline Total polyphenols (mg gallic acid/100 g wine powder) & $801 \pm 72^{\mathrm{a}}$ & $1958 \pm 286^{\mathrm{b}}$ \\
\hline Water activity (aw) & $0.21 \pm 0.01$ & $0.25 \pm 0.00$ \\
\hline Moisture (\% w/w) & $4.1 \pm 0.10$ & $4.5 \pm 0.05$ \\
\hline Solubility (\%) & $97 \pm 0.40$ & $99 \pm 0.20$ \\
\hline
\end{tabular}

$*$ Means \pm SD $(n=3)$. Different letters in the same row indicate significant differences $(p<0.05$, Tukey HSD Test, $\alpha=0.05)$.

It is to be noted that percent yield in samples of Ancellotta spray-dried with MD10 averaged $59 \pm 3 \%$, which is similar to previous studies with C. sauvignon wine [16]. The high solubility of the spray dried Ancellotta wine (Table 2) is one important parameter regarding its potential application in liquid matrices. 
Fig 1 compares the visual color of liquid wine and spray dried wine for both Ancellotta and C. sauvignon. The high anthocyanin content of the Ancellotta variety is reflected in its intense coloration.

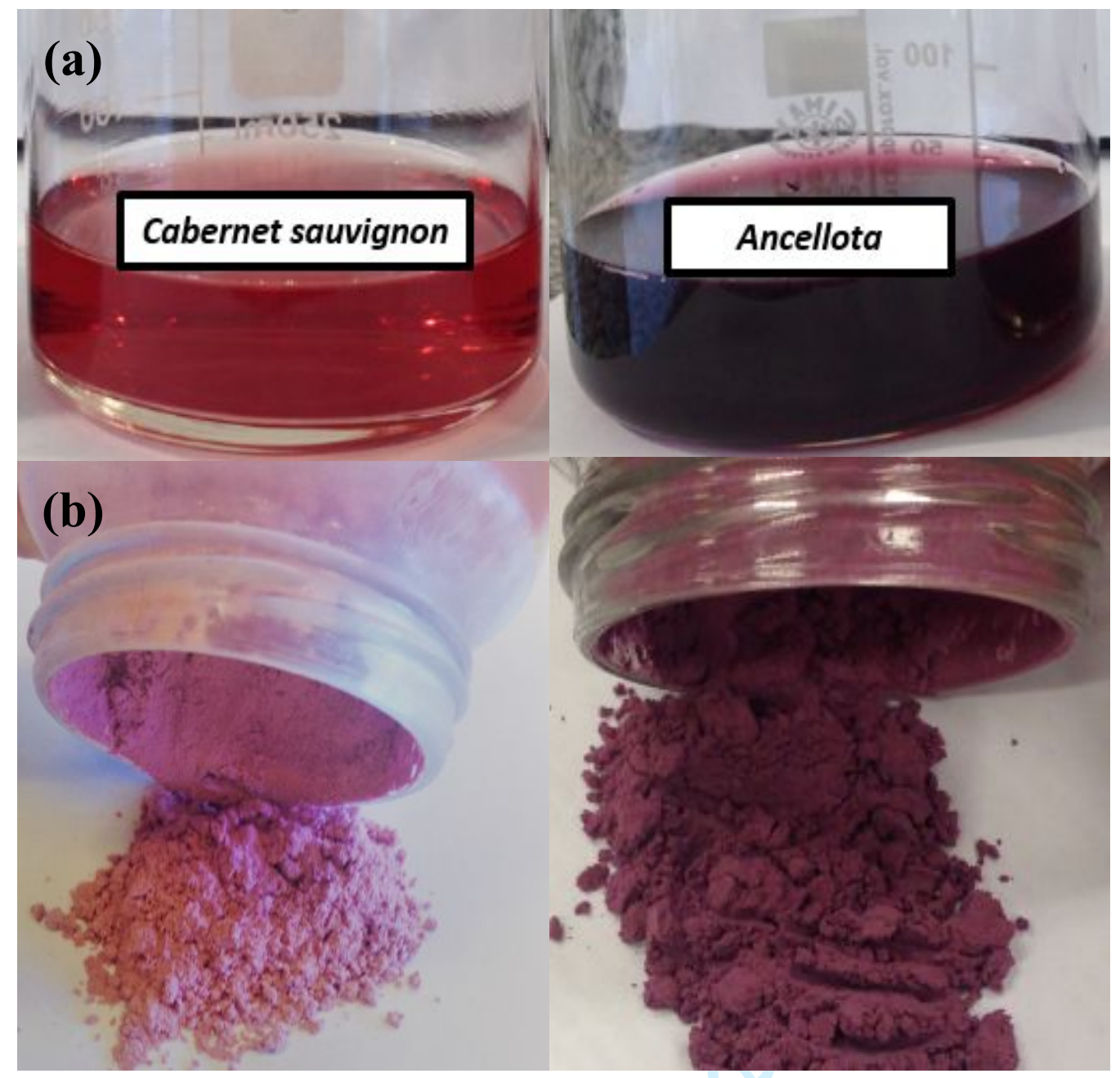

Fig 1 Visual color comparison of Cabernet sauvignon and Ancellotta wines diluted 1:10 (a) and their spray dried powders (b)

Fig 2 shows scanning electron micrographs (SEM, x 10,000) of Ancellotta wine powder encapsulated with DE10 maltodextrin (dried at $145^{\circ} \mathrm{C}$ ). 
During the spray-drying process of Ancellotta wine, the maltodextrin forms a layer on the surface of the drop, which can be seen in scanning electron micrographs (SEM) of the spray-dried Ancellotta wine (Fig 2). The SEM image show that maltodextrin enabled the formation of homogeneous capsules and polyphenols were encapsulated by the MD within a typical morphology for microcapsules. They visually appear a little dented with a rounded outer surface at x10,000 magnifications. The formation of these indentations on the surface (of particles obtained by spray-drying) is usually attributed to particle shrinkage due to the drastic loss of moisture followed by cooling [25, 26].

The anthocyanin profiles of the Ancellotta liquid wine and the powder were determined by HPLC-DAD and the results are shown in Table 3. There is little literature about phenolic composition of the Ancellotta variety and its relationship with other international red varieties. However, some studies have shown higher levels of anthocyanins in this variety compared to other Italian cultivars [27-29]. In the present study, the mean proportions of different families in wine samples were $63.2 \%$ for glucosylated, $17.4 \%$ for acetylated, $8.1 \%$ for cinnamoylated, and $11.4 \%$ for pyranoanthocyanins and adducts (flavanol-anthocyanins) (Table 3).

Additionally, the mean values obtained for the ratios $\Sigma$ glucosylated/ $/$ acetylated,

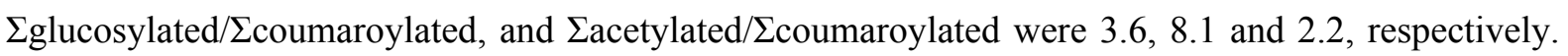
These results shown a pattern similar to that of Malbec, a red cultivar very important for Argentinian wine industry and characterized previously by Fanzone [30]. The effect of spray-drying, the ratio of the concentration (100 g of powder/100 g of liquid wine) was calculated for each anthocyanin. The ratio observed for each individual compound ranged between 4.1 and 17.9, with an average value of about 
7.2. It is noticeable, that the cyanidin and malvidin derivatives were the most concentrate compounds, 10.2 and 7.2 fold, respectively, in relation to the rest of compounds.

Table 3 Anthocyanins profile (HPLC-DAD) of Ancellotta liquid wine (mg /100 g) and wine powder $(\mathrm{mg} / 100 \mathrm{~g})$

\begin{tabular}{|c|c|c|c|c|}
\hline Compounds & $\begin{array}{l}\text { Ancellotta } 2015 \\
\text { liquid wine }\end{array}$ & & $\begin{array}{c}\text { Ancellotta } 2015 \\
\text { wine powder }\end{array}$ & \\
\hline Delphinidin-3-glucoside & $7.55 \pm 0.73 \quad \bar{a}-1$ & a & $35.97 \pm 2.34$ & b \\
\hline Cyanidin-3-glucoside & $1.24 \pm 0.12$ & a & $6.96 \pm 0.45$ & b \\
\hline Petunidin-3-glucoside & $8.06 \pm 0.78$ & a & $39.10 \pm 2.55$ & $\mathrm{~b}$ \\
\hline Peonidin-3-glucoside & 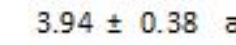 & a & $19.06 \pm 1.24$ & b \\
\hline Malvidin-3-gluc oside & $20.64 \pm 2.00=$ & a & $108.21 \pm 7.05$ & $\mathrm{~b}$ \\
\hline Total non-acylated & $41.43 \pm 4.00$ & a & $209.30 \pm 13.64$ & $\mathrm{~b}$ \\
\hline Delphinidin-3-(6"-acetyl)-glucoside & $2.62 \pm 0.25$ & $a$ & $13.13 \pm 0.86$ & $\mathrm{~b}$ \\
\hline Cyanidin-3-(6"-acetyl)-glucoside & $0.91 \pm 0.09 \bar{c}$ & a & $5.55 \pm 0.36$ & $\mathrm{~b}$ \\
\hline Petunidin-3-(6"-acetyl)-glucoside & $2.50 \pm 0.24$ & a & $12.44 \pm 0.81$ & b \\
\hline Peonidin-3-(6"-acetyl)-glucoside & $0.74 \pm 0.07$ & a & $4.57 \pm 0.30$ & $\mathrm{~b}$ \\
\hline Malvidin-3-(6"-acety)-gluc oside & $4.61 \pm 0.45$ & a & $22.78 \pm 1.48$ & $\mathrm{~b}$ \\
\hline Total acetylated & $11.38 \pm 1.10$ & $a$ & $58.47 \pm 3.81$ & $\mathrm{~b}$ \\
\hline Delphinidin-3-(6"-p-coumaroyl)-glucoside & $0.85 \pm 0.08$ & $a$ & $5.05 \pm 0.33$ & $\mathrm{~b}$ \\
\hline Cyanidin-3-(6"-p-coumaroyl)-glucoside & $0.13 \pm 0.01 \bar{a}-1-10$ & a & $2.07 \pm 0.13$ & b \\
\hline Petunidin-3-(6"-p-coumar oyl)-glucoside & $0.69 \pm 0.07 \bar{c}$ & $a$ & $3.44 \pm 0.22$ & $\mathrm{~b}$ \\
\hline Peonidin-3-(6"-p-coumaroyl)-glucoside & $0.82 \pm 0.08=$ & a & $3.20 \pm 0.21$ & b \\
\hline Malvidin-3-(6"-caffeoy 1$)$-glucoside & $0.16 \pm 0.02=$ & a & $2.02 \pm 0.13$ & b \\
\hline Malvidin-3-(6"-p-coumaroyl)-glucoside & $2.64 \pm 0.26 \mathrm{a}$ & a & $9.94 \pm 0.65$ & $\mathrm{~b}$ \\
\hline Total cinnamoylated & $5.28 \pm 0.51$ & a & $25.73 \pm 1.68$ & $\mathrm{~b}$ \\
\hline 10-H-pyr anoma lvid in-3-(6 "-acetyl)-glucoside & $0.82 \pm 0.08=$ & $\mathrm{a}$ & $5.52 \pm 0.36$ & $\mathrm{~b}$ \\
\hline 10-carboxy-pyr anodel phin idin-3-glucoside & $0.46 \pm 0.04 \quad \bar{a} \quad$ & a & $3.26 \pm 0.21$ & $\mathrm{~b}$ \\
\hline 10-carboxy-pyr anopet unidin-3-glucoside & $0.74 \pm 0.07 \quad$ & a & $5.04 \pm 0.33$ & b \\
\hline 10-carboxy-pyr anopeonid in-3-glucos ide & $0.60 \pm 0.06$ & a & $6.45 \pm 0.42$ & b \\
\hline 10-carboxy-pyr anomalvid in-3-glucoside & $1.11 \pm 0.11 \bar{a}$ & a & $6.45 \pm 0.42$ & b \\
\hline 10-carboxy-pyr anoma lvid in-3-(6"-acetyl)glucoside & $1.19 \pm 0.11=$ & a & $6.90 \pm 0.45$ & $\mathrm{~b}$ \\
\hline Total vitisin-like pyranoanthocyanins & $4.92 \pm 0.48=$ & $a$ & $33.62 \pm 2.19$ & $\mathrm{~b}$ \\
\hline 10-hydroxyphenyl-pyranomalvidin-3-glucoside & $0.36 \pm 0.04 \quad a$ & a & $2.20 \pm 0.14$ & b \\
\hline 10-hydroxyphenyl-pyranomalvidin-3-(6"-acetyl)-glucoside & $0.17 \pm 0.02$ & & ND & \\
\hline 10-hydroxyphenyl-pyranomalvid in-3-(6"-p-coumar oyl)-glucos ide & $0.11 \pm 0.01$ & & ND & \\
\hline 10-methoxy-hydroxyphenyl-pyranomalvidin-3-glucoside & $0.23 \pm 0.02$ & & ND & \\
\hline Total hydroxyphenyl-pyranoanthocyanins & $0.87 \pm 0.08 \mathrm{a}$ & a & $2.20 \pm 0.14$ & $\mathrm{~b}$ \\
\hline Malvidin-3-glucoside-catechin & 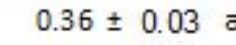 & a & $3.58 \pm 0.23$ & b \\
\hline Malvidin-3-glucoside-ethyl-catechin & $1.34 \pm 1.34 \quad \bar{a}$ & a & $7.13 \pm 0.46$ & \\
\hline Total fla vanol-anthocyanin adducts & $1.69 \pm 0.16$ a & a & $10.71 \pm 0.70$ & $\mathrm{~b}$ \\
\hline Total anthocyanins & $65.57 \pm 6.34 \quad \mathrm{a}$ & a & $340.02 \pm 22.15$ & $\mathrm{~b}$ \\
\hline
\end{tabular}


The water sorption isotherm of Ancellotta powder at $30^{\circ} \mathrm{C}$ is shown in Fig 3. Physical changes in the powder were observed with increasing the water activity level from aw 0.29 to aw 0.75 . At low water activity the powder remains free-flowing; at aw 0.43 the powder formed lumps and at aw 0.58 and above it completely collapses. This behavior can be explained by considering that physical changes in the amorphous wine powder matrix depends on time and are a function of $(\mathrm{T}-\mathrm{Tg})$, where $\mathrm{T}$ is the storage temperature and $\mathrm{Tg}$ is the glass transition temperature [16]. Between water activity of aw 0.43 and aw 0.58 a small plateau was observed which could be attributed to crystallization of wine tartrates.

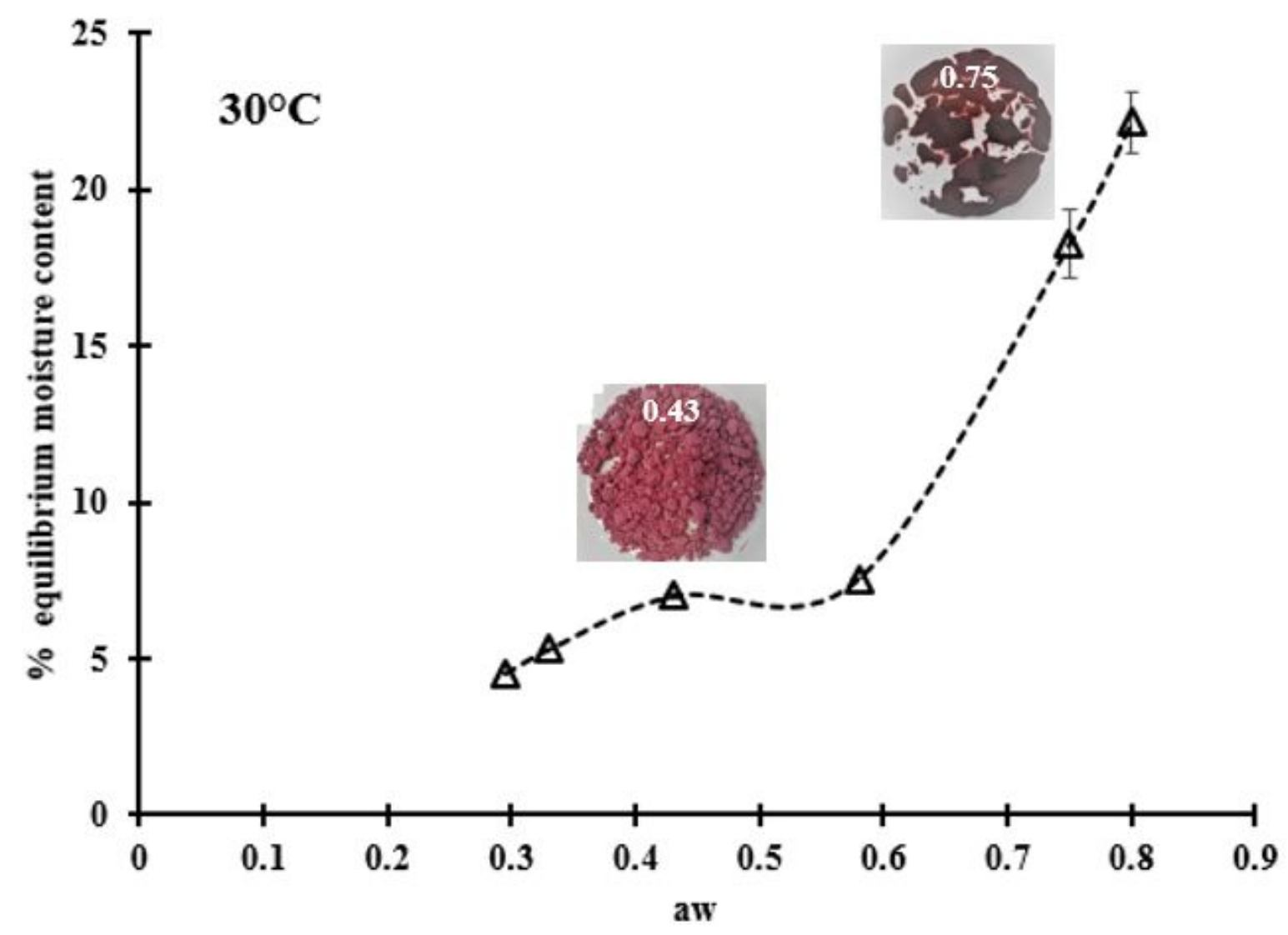

Fig 3 Adsorption isotherm at $30^{\circ} \mathrm{C}$ of Ancellotta wine powder. Error bars overlapped with some data points. A few pictures were inserted to show the physical changes associated with water activity

The stability of anthocyanins in Ancellotta wine powder during storage at $38^{\circ} \mathrm{C}$ and two different water activities (aw 0.25 and aw 0.33) was examined and results are presented in Fig 4. 


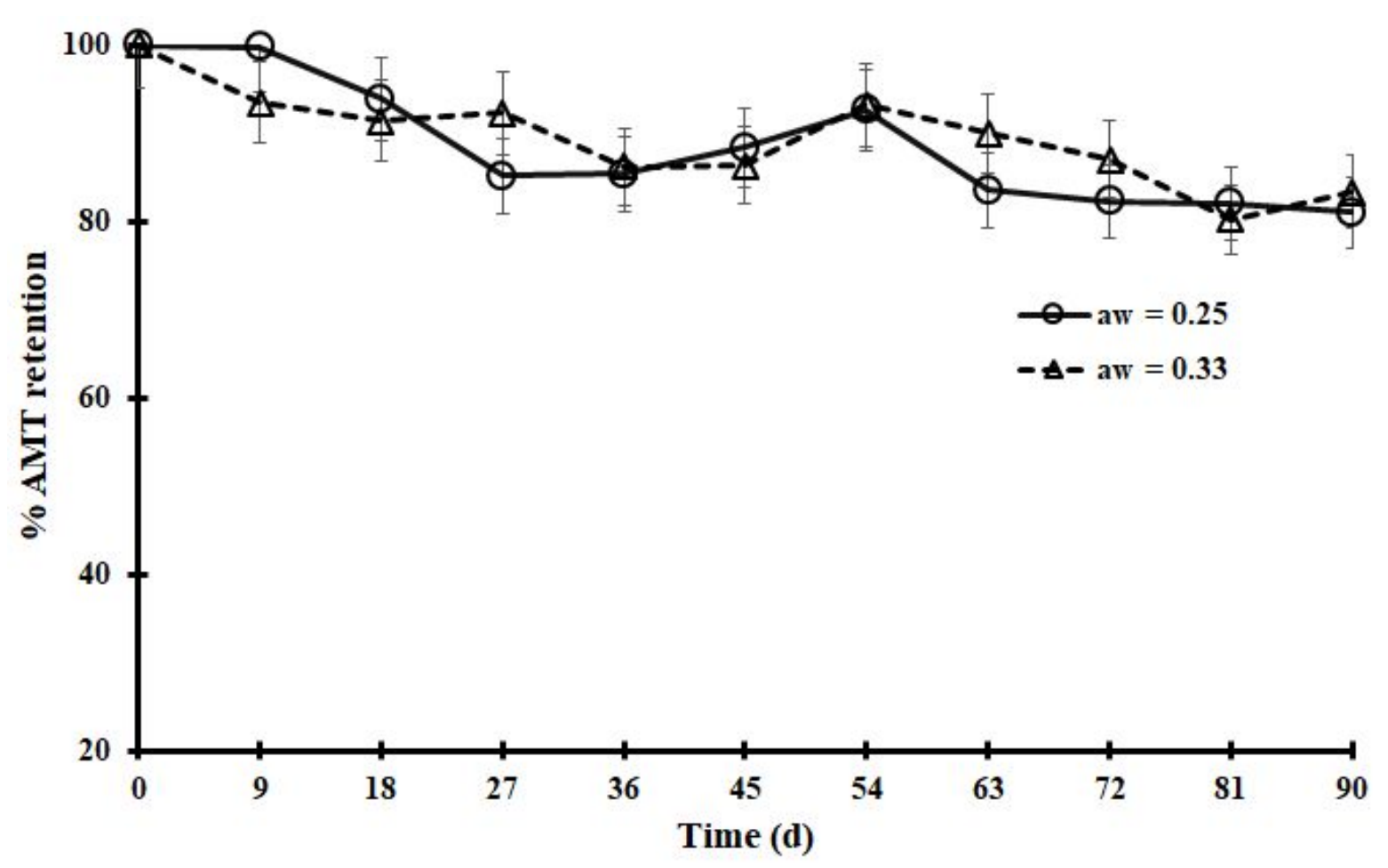

Fig 4 Stability of total monomeric anthocyanin (TMA) in spray-dried Ancellotta powder stored at 38 ${ }^{\circ} \mathrm{C}$ with two different values of water activity (aw 0.25 and aw 0.33 )

It is observed that after 90 days of storage at $38{ }^{\circ} \mathrm{C}$ the loss is only $20 \%$, as compared to the initial concentration. This behavior is consistent with previous literature results indicating that maintaining a low water activity value is critical for anthocyanin retention during storage [31].

The afforded mentioned behavior of total monomeric anthocyanins during storage was also examined by HPLC-DAD (in total anthocyanins and malvidin-3-glucoside contents) analysis and the results are shown in Fig 5. 


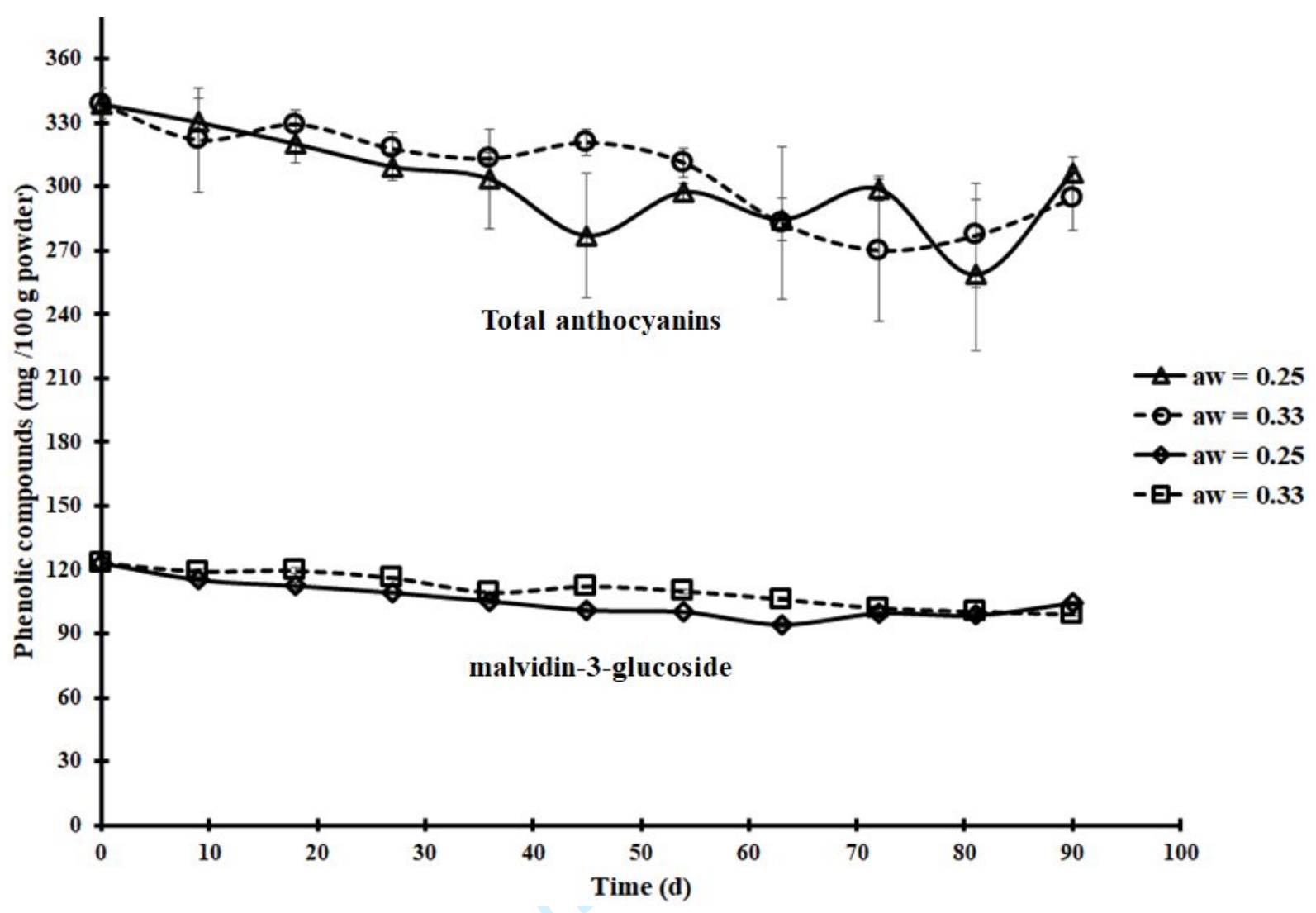

Fig 5 Stability of total anthocyanin and malvidin-3-glucoside in Ancellotta wine powder stored at 38 ${ }^{\circ} \mathrm{C}$ for two values of water activity (aw 0.25 and aw 0.33 ) determined by HPLC-DAD. Error bar overlapped with some data points

The behavior of malvidin-3-glucoside and total anthocyanins during storage at $38^{\circ} \mathrm{C}$ and water activity aw 0.25 and aw 0.33 is fairly similar to that previously shown (Fig 4) using pH differential method.

The total anthocyanins and malvidin-3-glucoside in the Ancellotta wine powder also decreased slightly with the time similarly to that observed with total monomeric anthocyanin.

The observed storage stability of total anthocyanins and malvidin-3-glucoside in the Ancellotta wine powder was associated with the protection afforded by powder matrix components; i.e. to act as a barrier to the permeation of detrimental substances like moisture and oxygen $[32,33]$.

The stability and equilibria of total anthocyanins and malvidin-3-glucoside in Ancellotta wine powder were also studied in aqueous solution at different $\mathrm{pH}$ values. As shown in Fig 6, the rate of total anthocyanins and malvidin-3-glucoside degradation increased up to its maximum value as temperature and $\mathrm{pH}$ increased from $5{ }^{\circ} \mathrm{C}$ to $60{ }^{\circ} \mathrm{C}$ and $\mathrm{pH} 3.0$ to 6.0 . It was observed that anthocyanin-containing in $1 \%$ wine powder solution displayed their most intense red coloration at acidic $\mathrm{pH} 3.0$ (data not shown), 
even holding a $1 \%$ wine powder solution at the acid $\mathrm{pH}$ values for a period as long as 47 hours, the red color of the solution retained its high stability at $5{ }^{\circ} \mathrm{C}$ and $30^{\circ} \mathrm{C}$. With increasing $\mathrm{pH}$ value of the solution up to 6.0, the red color greatly faded and almost appeared colorless even at a $\mathrm{pH}$ value of 3.0. The stability of anthocyanins was markedly influenced by heat treatment and $\mathrm{pH}$. The highest levels of the degradation for total anthocyanins and malvidin-3-glucoside were observed at $\mathrm{pH} 6.0$ and $60{ }^{\circ} \mathrm{C}$.

In conclusion, anthocyanins in $1 \%$ wine powder solution decreased with time in a temperaturedependent manner, with minimal loss at low temperature $\left(5^{\circ} \mathrm{C}\right)$ and higher loss at $60^{\circ} \mathrm{C}$. Moreover, if $\mathrm{pH}$ of solution increased the anthocyanins decreased with time. 

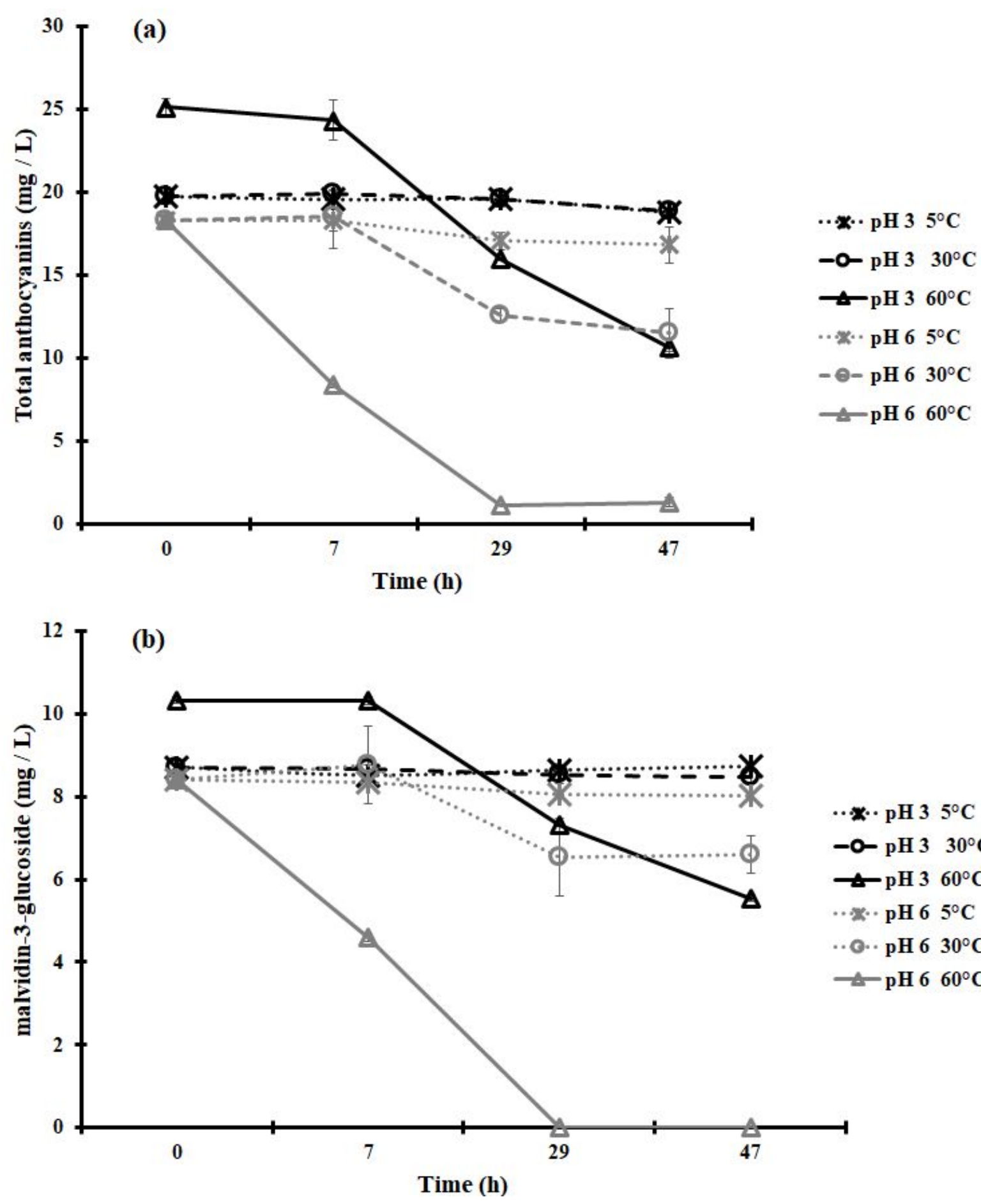

Fig 6 Stability of total anthocyanin (a) and malvidin-3-glucoside (b) in $1 \%$ wine powder solution containing $5 \%$ sucrose and stored 47 hours at $5{ }^{\circ} \mathrm{C}, 30^{\circ} \mathrm{C}$ and $60{ }^{\circ} \mathrm{C}$ for $\mathrm{pH} 3.0$ and $\mathrm{pH}$ 6.0. Error bars overlapped with some data points

\section{Color behavior of anthocyanins as a potential colorant}

It is widely known that $\mathrm{pH}$ strongly influences the color of anthocyanins [34]. This effect was examined in a $1 \%$ wine powder solution in which $\mathrm{pH}$ was set at 3.0 and 6.0. Fig 7 shows the photographic record of color modification. 
Depending on the $\mathrm{pH}$ of the medium, the red-colored flavylium cation coexists as an equilibrium mixture with other forms of anthocyanins: the blue-purple quinonoidal bases, the colorless hemiacetal $\mathrm{B}$, and the pale yellow chalcones. Therefore, the same anthocyanin solution may show a different color. It is also known that at $\mathrm{pH} 3.0$ color is more stable than a higher $\mathrm{pH}[34,35]$.

As mentioned before, utilization of anthocyanins as food colorants have two main drawbacks: a) in aqueous medium anthocyanins undergo reversible structural transformations $\mathrm{pH}$ dependent, with concomitant change in color [8-10]; b) the thermal instability of anthocyanins during food processing and storage acts as an impediment to their use. These problems could be avoided using Ancellotta powder as a colorant, for example, in food powders having low water activity and $\mathrm{pH}$. For example, popular fruit drink powders are known to have $\mathrm{pH}$ close to 3.0 and water activity about aw $=0.30$ (unpublished results) which will protect anthocyanins.

In order to establish whether the observed changes in the CIELAB parameters were visually relevant, color variations between $1 \%$ wine powder solutions (containing $5 \%$ sucrose) at $\mathrm{pH} 3.0$ (a) and 6.0 (b), during storage at $5{ }^{\circ} \mathrm{C}, 30^{\circ} \mathrm{C}$ and $60{ }^{\circ} \mathrm{C}$, were calculated and expressed as colorimetric differences $\Delta \mathrm{E}^{*}{ }_{\mathrm{ab}}$ (Fig 8). Moreover, the figure shows the relative contribution of Lightness, Chroma and Hue $\left(\Delta \mathrm{L}^{\prime}\right.$, $\left.\Delta \mathrm{C}^{\prime}, \Delta \mathrm{H}^{\prime}\right)$ to each color difference, what allows evaluating which color attribute was the most influenced. According to Martinez et al. [36], $\Delta \mathrm{E}^{*}{ }_{\mathrm{ab}}$ around 3 units indicates, the color differences detectable by the human eye (as an average observer). On this basis, the most perceptible color changes were produced when the $\mathrm{pH}$ and temperature were increased, observing the highest $\Delta \mathrm{E}^{*}{ }_{\text {ab }}$ values at 60 ${ }^{\circ} \mathrm{C}$ and pH 6.0, indicating greater color degradation (Fig 8b). This data is also in agreement with the aforementioned results for phenolic compounds and total monomeric anthocyanins. As can be seen in 
the Fig 8a, at $\mathrm{pH} 3.0$ and $60{ }^{\circ} \mathrm{C}$ the main difference was qualitative, evidenced by the significantly higher contribution of hue $\% \Delta^{2} \mathrm{H}(87-93 \%)$, with respect to lightness $\% \Delta^{2} \mathrm{~L}$ or chroma $\% \Delta^{2} \mathrm{C}(1-12 \%$ and 1-6\%, respectively). On the other hand, at pH 6.0 (Fig 8b) the quantitative color changes $\left(\% \Delta^{2} \mathrm{C}\right)$ became more pronounced, especially for range time 0-47 hours, and a higher temperatures values. Between time-lapse 0-29 and 0-47 hours the chroma modifications $\% \Delta^{2} \mathrm{C}$ (52\% in both range time) were particularly more marked than hue $\% \Delta^{2} \mathrm{H}(\approx 40 \%$ in both range time $)$ at $60{ }^{\circ} \mathrm{C}$. Therefore, a wine powder solution at $\mathrm{pH} 3.0$ and $\mathrm{pH} 6.0$ maintaining at $60^{\circ} \mathrm{C}$ promote a visual color change from brilliant red to more brownish hues. In contrast, samples kept at $5{ }^{\circ} \mathrm{C}$ maintained attractive colors even after 47 hours of storage. Cevallos-Casals and Cisneros-Zevallos [37] reported that after 41 hours in aqueous extracts of Andean purple corn and red-fleshed sweet potato, all quinonoidal structures decreased their absorbances significantly. The color of these unstable quinonoidal bases increasingly shifted towards brown and yellow with time. After 138 days, yellow colorless structures predominated for all extracts at $\mathrm{pH}>4.0$. Extracts at $\mathrm{pH} 1.0$ and 3.0 were selected, due to their higher stability as determined previously. 

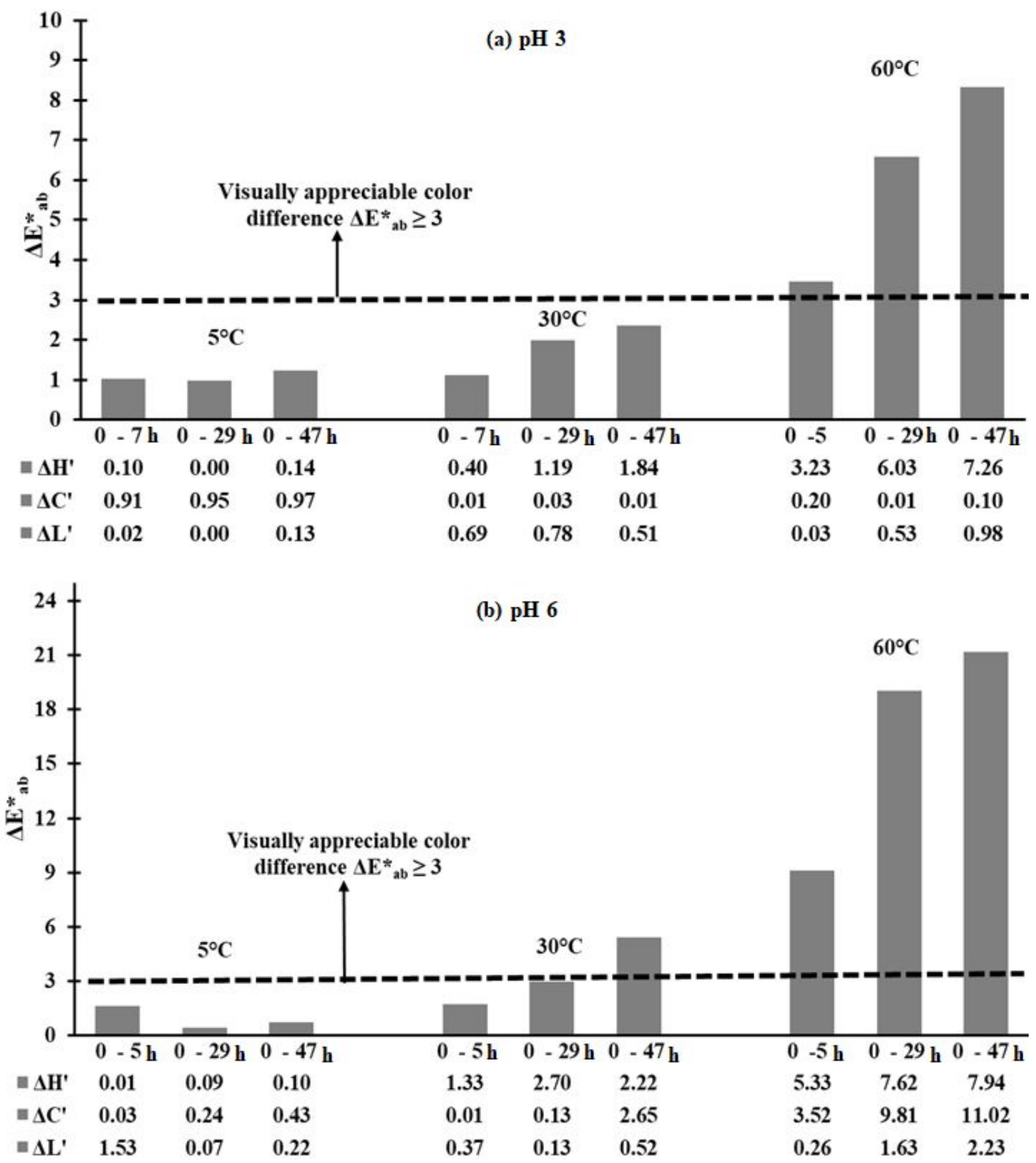

Fig 8 Color differences $\left(\Delta \mathrm{E}^{*}{ }_{\mathrm{ab}}\right)$, showing the relative contribution of Lightness, Chroma and Hue ( $\Delta \mathrm{L}^{\prime}$, $\left.\Delta \mathrm{C}^{\prime}, \Delta \mathrm{H}^{\prime}\right)$, in $1 \%$ wine powder solution containing $5 \%$ sucrose and $\mathrm{pH}$ values of $\mathrm{pH} 3.0$ (a) and $\mathrm{pH} 6.0$ (b) 


\section{Conclusions}

Ancellotta wine containing a fairly high amount of anthocyanins, was spray-dried with maltodextrin to obtain a free-flowing powder having an intense color. The stability of anthocyanin compounds (determinated by HPLC-DAD) in wine powder having water activity aw 0.33 or less was found to be remarkably good. For this reason, it could be used as a color of natural origin in products such as the popular "fruit drink powders", since these products have a low water activity and a very favorable $\mathrm{pH}$ (3.0). In addition to contain a high concentration of anthocyanins and other phenolic compounds, the wine powder maybe useful in preparation of healthy foods since it would contain the polyphenols of red wine, but without the presence of alcohol.

\section{Conflict of Interest}

The authors declare that they have no conflict of interest.

\section{Compliance with ethics requirements}

This article does not contain any studies with human or animal subjects. 


\section{References}

1. Griffiths J (2005) Coloring foods \& beverages. Food Technol 59(5): 38-44.

2. McCann D, Barrett A, Cooper A, Crumpler D, Dalen L, Grimshaw K, Kitchin E, Lok K, Porteous L, Prince E (2007) Food additives and hyperactive behaviour in 3-year-old and 8/9-year-old children in the community: a randomised, double-blinded, placebo-controlled trial. LANCET 370(9598): 1560-1567.

3. He J, Giusti MM (2010) Anthocyanins: natural colorants with health-promoting properties. Annu Rev Food Sci T 1: 163-187.

4. Heinonen J, Farahmandazad H, Vuorinen A, Kallio H, Yang B, Sainio T (2016) Extraction and purification of anthocyanins from purple-fleshed potato. Food Bioprod Process 99: 136-146.

5. Wang W, Jung J, Tomasino E, Zhao Y (2016) Optimization of solvent and ultrasound-assisted extraction for different anthocyanin rich fruit and their effects on anthocyanin compositions. LWT-Food Sci Technol 72: 229-238.

6. Ghosh D, Konishi T (2007) Anthocyanins and anthocyanin-rich extracts: role in diabetes and eye function. Asia Pac J Clin Nutr 16(2): 200-208.

7. Wang LS, Stoner GD (2008) Anthocyanins and their role in cancer prevention. Cancer Lett 269(2): 281-290.

8. Chandrasekhar J, Madhusudhan MC, Raghavarao KSMS (2012) Extraction of anthocyanins from red cabbage and purification using adsorption. Food Bioprod Process 90(4): 615-623.

9. Valls J, Millán S, Martí MP, Borràs E, Arola L (2009) Advanced separation methods of food anthocyanins, isoflavones and flavanols. J Chromatogr A 1216(43): 7143-7172.

10. Patil G, Madhusudhan MC, Babu BR, Raghavarao KSMS (2009) Extraction, dealcoholization and concentration of anthocyanin from red radish. Chem Eng Process 48(1): 364-369.

11. Stintzing FC, Carle R (2004) Functional properties of anthocyanins and betalains in plants, food, and in human nutrition. Trends Food Sci Tech 15(1): 19-38. 
12. Monagas M, Bartolomé B (2009) Anthocyanins and anthocyanin-derived compounds. In: Wine chemistry and biochemistry, 1st edn. Springer, New York, pp 439.

13. Masters K (1991) Spray drying handbook. Longman Scientific \& Technical; New York

14. Tonon RV, Brabet C, Hubinger MD (2010) Anthocyanin stability and antioxidant activity of spraydried açai (Euterpe oleracea Mart.) juice produced with different carrier agents. Food Res Int 43(3): 907-914.

15. Mahdavi SA, Jafari S M, Ghorbani M, Assadpoor E (2014) Spray-drying microencapsulation of anthocyanins by natural biopolymers: A review. Dry Technol 32(5):509-518.

16. Alvarez Gaona IJ, Bater C, Zamora MC, Chirife J (2017) Spray drying encapsulation of red wine: Stability of total monomeric anthocyanins and structural alterations upon storage. J Food Process Pres 42(2): e13457.

17. Labuza TP (1982) Shelf-life dating of foods. Food Nutr Press, Inc., Connecticut

18. Favetto G, Resnik S, Chirife J, Fontan CF (1983) Statistical evaluation of water activity measurements obtained with the Vaisala Humicap humidity meter. J Food Sci 48(2): 534-538.

19. AOAC (1995) Official methods of analysis. Arlington, USA.

20. Camussoni G, Carnevali E (2004) Determinación comparativa del contenido de polifenoles en vinos tintos de origen. In: Invenio 7 (13): 151-160.

21. Cioroi M, Musat CL (2007) Investigations on the correlations between polyphenol content from red wines and their antioxidant capacity. Cercetari Agronomice in Moldova 4: 35-42.

22. Giusti MM, Wrolstad RE (2001) Characterization and measurement of anthocyanins by UV-visible spectroscopy. Current Protocols in Food Analytical Chemistry 00: F1.2.1-F1.2.13.

23. Iglesias HA, Chirife J (1976). Equilibrium moisture contents of air dried beef. Dependence on drying temperature. Int J Food Sci Tech 11(6): 565-573. 
24. Blanco-Vega D, López-Bellido FJ, Alía-Robledo JM, Hermosín-Gutiérrez I (2011) HPLC-DADESI-MS/MS characterization of pyranoanthocyanins pigments formed in model wine. J Agr Food Chem 59(17): 9523-9531.

25. Saénz C, Tapia S, Chávez J, Robert P (2009) Microencapsulation by spray drying of bioactive compounds from cactus pear (Opuntia ficus-indica). Food Chem 114(2): 616-622.

26. Tonon RV (2009) Secagem por atomização do suco de açaí: influência das variáveis de processo, qualidade e estabilidade do produto. Ph.D. Thesis, Universidade Estadual de Campinas, Campinas, 28-29 p

27. Malinovski LI, Brighenti AF, Borghezan M, Guerra MP, Silva AL, Porro D, Vieira HJ (2016, August). Viticultural performance of Italian grapevines in high altitude regions of Santa Catarina State, Brazil. In Acta Hortic 1115: 203-210

28. Ragone R, Crupi P, Piccinonna S, Bergamini C, Mazzone F, Fanizzi FP, Schena FP, Antonacci D (2015). Classification and chemometric study of Southern Italy monovarietal wines based on NMR and HPLC-DAD-MS. Food Sci Biotechnol 24(3): 817-826.

29. Sartor S, Caliari V, Malinovski LI, Toaldo IM, Bordignon-Luiz MT (2017) Bioactive profiling of polyphenolics and oenological properties of red wines from Italian grapes (Vitis vinifera L.) cultivated in a selected subtropical region. Int J Food Prop 20(2): 1319-1328.

30. Fanzone M, Zamora F, Jofré V, Assof M, Gómez-Cordovés C, Peña-Neira Á (2012) Phenolic characterisation of red wines from different grape varieties cultivated in Mendoza province (Argentina). J Sci Food Agr 92(3): 704-718.

31. Rocha-Parra DF, Lanari MC, Zamora MC, Chirife J (2016) Influence of storage conditions on phenolic compounds stability, antioxidant capacity and color of freeze-dried encapsulated red wine. LWT-Food Sci Technol 70: 162-170.

32. Wagner LA, Warthesen JJ (1995) Stability of spray-dried encapsulated carrot carotenes. J Food Sci 60(5): 1048-1053.

33. Serris GS, Biliaderis CG (2001) Degradation kinetic of beet root pigment encapsulated polymeric matrices. J Sci Food Agr 81: 691-700. 
34. Heredia FJ, Francia-Aricha EM, Rivas-Gonzalo JC, Vicario IM, Santos-Buelga C (1998) Chromatic characterization of anthocyanins from red grapes-I. pH effect. Food Chem 63(4): 491-498.

35. Brouillard R (1982) Chemical structure of anthocyanins. In Anthocyanins as Food Colors. Academic Press, New York, pp 1-38.

36. Martínez JA, Melgosa M, Pérez MM, Hita E, Negueruela AI (2001) Note. Visual and instrumental color evaluation in red wines. Food Sci Technol Int 7(5): 439-444.

37. Cevallos-Casals BA, Cisneros-Zevallos L (2004) Stability of anthocyanin-based aqueous extracts of Andean purple corn and red-fleshed sweet potato compared to synthetic and natural colorants. Food Chem 86(1): 69-77. 